\title{
MFIX Documentation Theory Guide
}

\author{
Technical Note
}

\author{
Madhava Syamlal \\ William Rogers \\ Thomas J. O'Brien
}

\author{
U.S. Department of Energy \\ Office of Fossil Energy \\ Morgantown Energy Technology Center \\ P.O. Box 880 \\ Morgantown, West Virginia 26507-0880
}

December 1993 


\section{Contents}

Page

Executive Summary $\ldots \ldots \ldots \ldots \ldots \ldots \ldots \ldots \ldots \ldots \ldots \ldots \ldots \ldots$

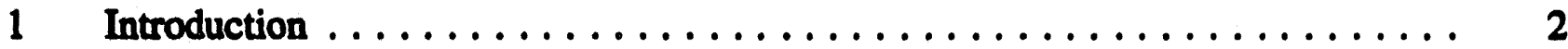

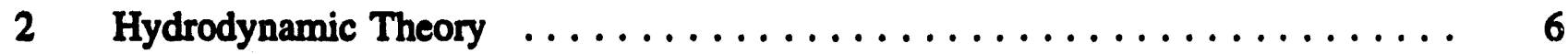

2.1 Conservation of Mass . . . . . . . . . . . . . . . . . 7

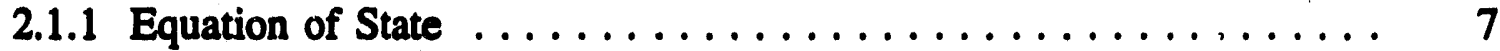

2.2 Conservation and Momentum $\ldots \ldots \ldots \ldots \ldots \ldots \ldots \ldots \ldots$

2.2.1 Fluid-Solids Momentum Transfer . . . . . . . . . . . . . 8

2.2.2 Solids-Solids Momentum Transfer . . . . . . . . . . . . . . . . 11

2.2 .3 Fluid-Phase Stress Tensor . . . . . . . . . . . . . . . . . . . 12

2.2.4 Solids-Phase Stress Tensor . . . . . . . . . . . . . . . . . . . 12

2.3 Conservation of Internal Energy $\ldots \ldots \ldots \ldots \ldots \ldots \ldots$

2.3.1 Fluid-Solids Heat Transfer . . . . . . . . . . . . . . . . . 18

2.3.2 Conductive Heat Flux in Fluid Phase . . . . . . . . . . . . . 19

2.3.3 Conductive Heat Flux in Solids Phase . . . . . . . . . . . . . 19

2.3.4 Heat of Reaction ....................... 20



2.4 .1 Reaction Kinetics . . . . . . . . . . . . . . . . . 22

2.5 Conservation of Granular Energy . . . . . . . . . . . . . . . . . 24

2.5.1 Diffusive Flux of Granular Energy . . . . . . . . . . . . . 27

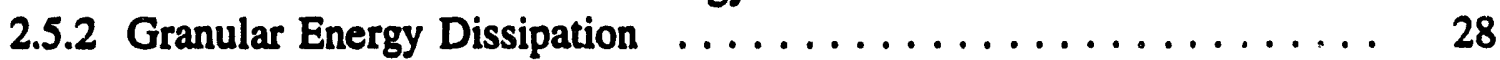

2.5.3 Granular Energy Transfer .................... 28

2.6 Initial and Boundary Conditions $\ldots \ldots \ldots \ldots \ldots$





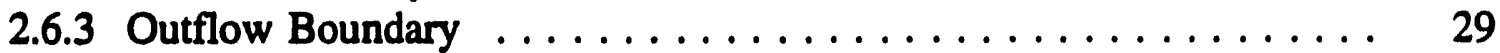

2.6 .4 Impermeable Walls . . . . . . . . . . . . . . . . . . . . 29

2.6.5 Impermeable and Semipermeable Internal Surfaces . . . . . . . . . . 29

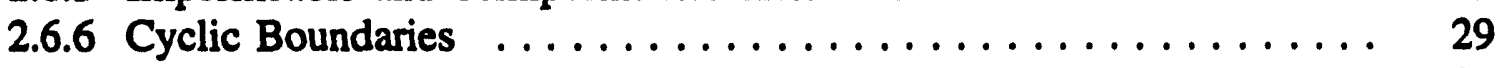

2.6 .7 Wall Heat Transfer . . . . . . . . . . . . . . . . . . . . 30

2.6.8 Boundary Conditions for Granular Energy Equation . . . . . . . . 30 
Contents

(Continued)

Page

3 Summary of Governing Equations and Constitutive Relations . . . . . . . . 31

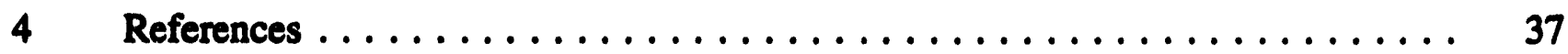

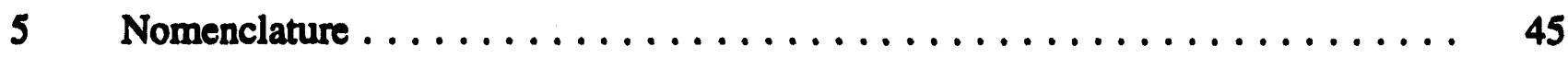

\section{List of Figures}

Fiqure

Page

1 Multiphase Descriptions of a Fluid-Solids Mixture . . . . . . . . . . 3

2 Slowly and Rapidly Shearing Granular Flows . . . . . . . . . . . . . . . 13

- 3 Energy Cascade in Granular Flows Compared With That in Turbulent

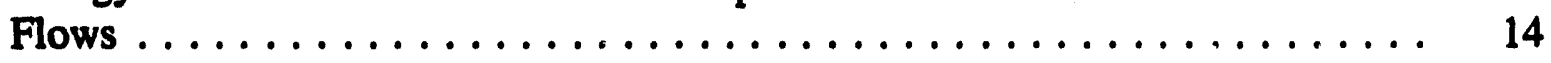

4 Computation of Heat of Reaction for Reactants at Different Temperatures ... 21

5 Shrinking Core Model for Coal Combustion . . . . . . . . . . . . . . 23 


\section{Executive Summary}

This report describes the MFIX (Multiphase Flow with Interphase eXchanges) computer model. MFIX is a general-purpose hydrodynamic model that describes chemical reactions and heat transfer in dense or dilute fluid-solids flows, flows typically occurring in energy conversion and chemical processing reactors. MFIX calculations give detailed information on pressure, temperature, composition, and velocity distributions in the reactors. With such information, the engineer can visualize the conditions in the reactor, conduct parametric studies and what-if experiments, and, thereby, assist in the design process.

The MFIX model, developed at the Morgantown Energy Technology Center (METC), has the following capabilities: mass and momentum balance equations for gas and multiple solids phases; a gas phase and two solids phase energy equations; an arbitrary number of species balance equations for each of the phases; granular stress equations based on kinetic theory and frictional flow theory; a user-defined chemistry subroutine; three-dimensional Cartesian or cylindrical coordinate systems; nonuniform mesh size; impermeable and semipermeable internal surfaces; user-friendly input data file; multiple, single-precision, binary, direct-access, output files that minimize disk storage and accelerate data retrieval; and extensive error reporting.

This report, which is Volume 1 of the code documentation, describes the hydrodynamic theory used in the model: the conservation equations, constitutive relations, and the initial and boundary conditions. The literature on the hydrodynamic theory is briefly surveyed, and the bases for the different parts of the model are highlighted. 


\section{Introduction}

Dense multiphase flow reactors are part of many energy conversion and chemical processing units. In a circulating fluidized-bed combustor, for example, coal burns as it flows in a dense gas-solids mixture. Another example is the Fluid Catalytic Cracking (FCC) riser, in which oil contacts rapidly circulating catalyst particles and is converted into gasoline. Clearly, the hydrodynamics, heat transfer, reaction kinetics, and catalyst activity influence the performance of the reactor. The design of such reactors traditionally relies on data from laboratory-scale batch reactors or continuous pilot-scale units. Although many processes have been successfully scaled-up in this manner, some notable failures have occurred (Squires, Kwauk, and Avidan 1985; Krambeck et al. 1987). Also, in some cases the laboratory-scale units exhibit different hydrodynamic behavior than do large-scale units, and intermediate pilot-scale units are expensive to build and operate. Hydrodynamic models based on fundamental laws of mass, momentum, energy, and species conservation have the potential to fill the data gaps in the results of laboratory-or pilot-scale experiments and, thereby, to aid in the design of industrial reactors. The MFIX computer model is such a general-purpose hydrodynamic model capable of describing chemical reactions and heat transfer in dense or dilute fluid-solids flows.

The theoretical and numerical foundations of MFIX are based on a hydrodynamic theory of fluidization. Hydrodynamic models have been developed and applied to describe fluidization since the early 60's: Davidson (1961), Jackson (1963), Davidson and Harrison (1963), Murray (1965), Pigford and Baron (1965), Soo (1967), Anderson and Jackson (1967), Ruckenstein and Tzeculescu (1967), and Jackson (1970). In those studies, the hydrodynamic models were used to study the stability of fluidization or to explore the details of bubble motion; no attempt was made to solve the rather formidable set of partial differential equations constituting the model.

The advent of high-speed computers prompted attempts to solve these equations numerically. In the late 70's, two projects funded by the U.S. Department of Energy (DOE) were initiated to develop computer models of coal gasifiers based on the hydrodynamic equations. The CHEMFLUB code, developed by Systems, Science, and Software Inc., solves continuum equations (much like the MFIX equations) to describe gas and solids flow in fluidized-bed gasifiers (Garg and Pritchett 1975; Schneyer et al. 1981; Blake and Chen 1981; Richner et al. 1990). The FLAG code, developed by JAYCOR Inc., solves continuum equations to describe gas flow, but uses a particle-tracking method to describe solids flow (Scharff et al. 1982). Somewhat in parallel to those efforts, Professor Gidaspow and coworkers at the Illinois Institute of Technology (IIT) began to develop computer codes for describing fluidized beds by adopting numerical techniques introduced by Harlow and Amsden (1975) and incorporated in the K-FIX program (Rivard and Torrey 1977), which describes watersteam flow. The subject of such numerical modeling has been reviewed in detail by Gidaspow (1986).

As a result of the studies described in the previous paragraph, much progress has been made toward developing comprehensive computer codes for describing fluidized beds. Based 
on recent reports, the following is a list of institutions developing numerical models of fluidized beds that are similar to the MFIX code: Babcock and Wilcox Inc., Alliance Research Center (Burge 1991), Argonne National Laboratory (Lyczkowski and Bouillard 1989), Illinois Institute of Technology (IIT) (Ding and Gidaspow 1990), and Twente University of Technology (Kuipers et al. 1993).

Two-phase hydrodynamic models treat the fluid and the solids as two interpenetrating continua; all the particles are considered to be identical, characterized by an effective diameter and identical material properties. To describe phenomena such as particle segregation and elutriation, however, the models must account for at least two types of particles, where each particle type is characterized by a unique diameter and density. Such a multiparticle code was developed at IIT (Syamlal 1985) from the single-particle code of Gidaspow and Ettehadieh (1983). Following a suggestion of Soo (1967), each solids phase consists of the particles with identical particle density and diameter. (See figure 1.) For example, a mixture of two types of particles that differ in diameter or density or both is treated as composed of two distinct solids phases, each with its own set of governing hydrodynamic equations. A mixture, characterized by a distribution of particle diameters or densities or both, is described in terms of a number of solids phases with diameters and densities obtained by discretizing the distribution function. The IIT code was used to simulate segregation in a fluidized bed (Syamlal 1985), material separation in an electrofluidized bed (Shi, Gidaspow, and Wasan 1987), and the explosive dissemination of particles (Gidaspow et al. 1984).

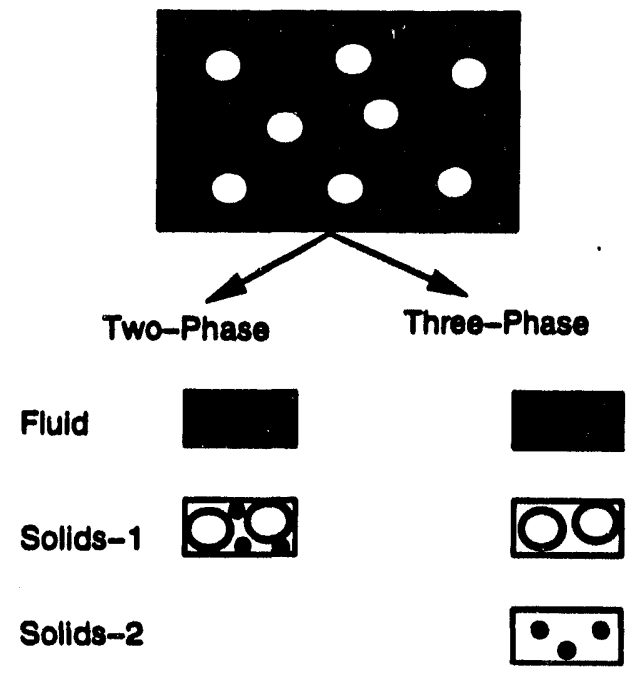

\section{Figure 1. Multiphase Descriptions of a Fluid-Solids Mixture}

The multiparticle code was further enhanced at METC by the addition of improved numerical algorithms, a solids pressure term, an improved drag correlation, and granular stress terms. A version of the code with thermal energy equations is called the NIMPF (NonIsothermal MultiParticle Fluidization) code (Syamlal 1987a; O'Brien and Syamlal 1990). The code has been used at METC since 1985 to predict the two-dimensional, non-isothermal, transient flows of the fluid and solids phases within a fluidized bed. Initially, the code was used to model fundamental fluidization phenomena, such as single-bubble injections, jet injections (Syamlal and O'Brien 1989), particle segregation (Syamlal and O'Brien 1988), and circulating fluidized-bed dynamics (O'Brien and Syamlal 1991; O'Brien and Syamlal 1993) -- 
all occurring in a nonreacting bed. These predictions were compared with experimental data for code verification. More recently, the code has been used to study increasingly complex and demanding fluidization conditions, including circulating fluidized-bed reactors, fluidized beds with immersed heat transfer tubes (Rogers and Boyle 1991), fluidized beds with a filter, and fluidized-bed reactors at high temperatures.

During its 6 years of METC service, the code continuously evolved to model these complex fluidization conditions. As part of this evolution, a project was undertaken to provide several much-needed enhancements to the code, as well as to compile and document all previous code modifications. The result of this project is the MFIX code, which has the following characteristics: mass and momentum balance equations for gas and multiple solids phases; a gas phase and two solids phase energy equations; an arbitrary number of species balance equations for each of the phases; granular stress equations based on kinetic theory and frictional flow theory; a user-defined chemistry subroutine; three-dimensional Cartesian or cylindrical coordinate systems; nonuniform mesh size; impermeable and semipermeable internal surfaces; user-friendly input data file; multiple, single-precision, binary, direct-access, output files that minimize disk storage and accelerate data retrieval; and extensive error reporting. In addition, two MFIX post-processor codes animate the results of the calculations and retrieve and manipulate data from the output files.

Hydrodynamic modeling has the remarkable ability to synthesize data from various, relatively simple experiments (for example, the drag on an isolated sphere or the volatilization rate measured using a single layer of coal particles) and, thereby, to describe the timedependent distribution of fluid and solids volume fractions, velocities, pressure, temperatures, and species mass fractions in industrial reactors, where measurement of such quantities might be all but impossible. Such calculations, therefore, allow the designer to visualize the conditions in the reactor, to understand how performance values change as operating conditions are varied, to conduct what-if experiments, and, thereby, to assist in the design process.

With such power also come several limitations that the user must bear in mind. First, the accuracy of the model's predictions may be limited for a variety of reasons: incomplete formulation of the governing equations, insufficient knowledge of the constitutive relations, unsatisfactory numerical treatment of the governing partial differential equations, insufficient information on initial and boundary conditions, and the impracticality of using a large number of nodes to resolve all the fine details of the flow. This implies the need for much crution when designing simulations and interpreting results. Often, trends predicted by the model are more useful than absolute values of various quantities.

A second limitation of hydrodynamic modeling is that an expert user is needed to conduct simulations and to analyze results. To assist the user, the present code resolves many of the difficulties in setting up simulations by using a special NAMELIST format in the input data file that reports input errors and allows comment lines. There is no limitation on the number of initial and boundary conditions. The code also does much run-time error reporting and has a graphical post-processor. In addition, these manuals describe the theory and use of the code in detail, so that with their help, someone with experience in computational fluid dynamics could become an expert user in about 3 months. 
A third limitation is that hydrodynamic modeling requires significant computer resources, although supercomputer facilities are not required. The availability of faster and cheaper computers has made hydrodynamic modeling more affordable. Workstations costing under $\$ 30,000$ have been sufficient for METC's simulation studies. Nonetheless, the user -must clearly define the results expected from the simulation and avoid needless refinements that increase computational time. Of course, the ultimate determinant should be the cost effectiveness of the approach.

This report describes the hydrodynamic theory used to formulate the code: the governing equations, constitutive relations, and the initial and boundary conditions. Other information is available from the authors, including descriptions of the procedure to set up simulations, to write input data files, to retrieve and visualize output data, and to interpret simulation results; some examples of typical applications; the procedure to numerically solve the governing equations; and the FORTRAN implementation of the numerical solution scheme. 


\section{Hydrodynamic Theory}

Assuming that the different phases can be mathematically described as interpenetrating continua, two distinct approaches can be used to derive the multiphase flow equations: the averaging approach and the mixture theory approach. In the averaging approach, the equations are derived by space, time, or ensemble averaging of the local, instantaneous balances for each of the phases (Anderson and Jackson 1967; Drew and Segel 1971; Ishii 1975; Joseph and Lundgren 1990). In the mixture theory approach, equations that are generalizations of single-phase equations are postulated (Bowen 1976; Passman, Nunziato, and Walsh 1983; Bedford and Drumheller 1983). Both approaches yield a similar set of balance equations that must be closed by specifying several constitutive relations, such as a fluid-phase equation of state, fluid-solids and solids-solids momentum transfer and heat transfer, and fluid and solids phase stress tensors. The principle of material frameindifference, the second axiom of thermodynamics, material symmetry, and over-all balance equations for the mixture yield several useful restrictions on such constitutive relations (Bowen 1976).

To proceed further toward solving practical problems of interest, it is necessary to supply specific constitutive relations. This challenging task is accomplished by using a variety of approaches, ranging from empirical information to kinetic theory. Most of the differences between multiphase theories originate from such closure assumptions, some of which are the subject of much debate. The governing equations developed here are based on various sources, as has been described in this section, but the pervading influence of Professor Jackson's work is evident.

Using the averaging approach to derive equations that describe interpenetrating continua, the point variables are averaged over a region that is large compared with the particle spacing but much smaller than the flow domain. New field variables, the phasic volume fractions, are introduced to track the fraction of the averaging volume occupied by various phases. These are denoted by $\varepsilon_{\mathrm{g}}$ for the fluid phase (also known as the void fraction) and $\varepsilon_{\mathrm{sm}}$ for the $\mathrm{m}^{\text {th }}$ solids phase. These volume fractions are assumed to be continuous functions of space and time. By definition, the volume fractions of all of the phases must sum to one:

$$
\varepsilon_{g}+\sum_{m=1}^{M} \varepsilon_{s m}=1
$$

where $\mathrm{M}$ is the total number of solids phases. The effective (macroscopic) density of the gas phase is

$$
\rho_{g}^{\prime}=\varepsilon_{g} \rho_{g}
$$


and that of the solids phase is

$$
\rho_{\mathrm{sm}}^{\prime}=\varepsilon_{\mathrm{am}} \rho_{\mathrm{am}},
$$

which, for a two-phase system, is the same as the bulk density. Just as the actual (microscopic) densities appear in single-phase equations, these effective densities appear in all of the multiphase equations.

\subsection{Conservation of Mass}

The continuity equation for the gas phase is

$$
\frac{\partial}{\partial t}\left(\varepsilon_{g} \rho_{g}\right)+\nabla \cdot\left(\varepsilon_{g} \rho_{g} \vec{\nabla}_{g}\right)=\sum_{n=1}^{N_{g}} R_{g n}
$$

There are $M$ solids-phase continuity equations, each of the form

$$
\frac{\partial}{\partial E}\left(\varepsilon_{\mathrm{sm}} \rho_{\mathrm{sm}}\right)+\nabla \cdot\left(\varepsilon_{\mathrm{sm}} \rho_{\mathrm{sm}} \vec{\nabla}_{\mathrm{em}}\right)=\sum_{\mathrm{m}=1}^{N} R_{\mathrm{emn}}
$$

The first term on the left in equations (4) and (5) accounts for the rate of mass accumulation per unit volume, and the second term is the net rate of convective mass flux. The term on the right accounts for interphase mass transfer because of chemical reactions or physical processes, such as evaporation. (See section 2.4.)

\subsubsection{Equation of State}

The fluid phase can be modeled as a gas obeying the ideal gas law,

$$
\rho_{g}=\frac{P_{g} M W}{R T_{g}},
$$

or as an incompressible fluid with a constant density. The user may specify any other equation of state by modifying the equation of state subroutine (EOSG).

\subsection{Conservation of Momentum}

The gas-phase momentum balance is expressed as

$$
\frac{\partial}{\partial t}\left(\varepsilon_{g} \rho_{g} \vec{v}_{g}\right)+\nabla \cdot\left(\varepsilon_{g} \rho_{g} \vec{v}_{g} \vec{v}_{g}\right)=\nabla \cdot \bar{S}_{g}+\varepsilon_{g} \rho_{g} \vec{g}-\sum_{m=1}^{n} \vec{I}_{g m}+\vec{f}_{g} ，
$$

where $\vec{S}_{g}$ is the gas-phase stress tensor, $\vec{I}_{g m}$ is an interaction force representing the momentum transfer between the gas phase and the $\mathrm{m}^{\text {th }}$ solids phase, and $\vec{E}_{g}$ is the flow resistance offered by internal porous surfaces. (See section 2.6.5.) The momentum equation for the $\mathrm{m}^{\text {th }}$ solids phase is 




where $\bar{S}_{a m}$ is the stress tensor for the $\mathrm{m}^{\text {th }}$ solids phase. The term $\overrightarrow{\mathrm{I}}_{\mathrm{lm}}$ is the interaction force between the $\mathrm{m}^{\mathrm{th}}$ and $\mathrm{l}^{\text {th }}$ solids phases. The first term on the left in these momentum equations represents the net rate of momentum increase. The second term on the left represents the net rate of momentum transfer by convection. The first term on the right represents normal and shear surface forces, while the second term represents body forces (gravity in this case). The next term in equation (7) represents the momentum transfer between the fluid and solids phases; the final term represents the momentum transfer between the fluid and a rigid porous structure. The last two terms in equation (8) represent the momentum exchange between the fluid and solids phases and between the different solids phases, from left to right.

\subsubsection{Fluid-Solids Momentum Transfer}

In the momentum conservation equations, (7) and (8), the term $\mathrm{I}_{\mathrm{gm}}$ accounts for the interaction force, or momentum transfer, between the gas phase and the $\mathrm{m}^{\text {th }}$ solids phase. The mechanisms and formulation of interaction forces have been reviewed in detail by Johnson, Massoudi, and Rajagopal (1990). From studies on the dynamics of a single particle in a fluid, several different mechanisms have been identified: drag force, caused by velocity differences between the phases; buoyancy, caused by the fluid pressure gradient; virtual mass effect, caused by relative acceleration between phases; Saffman lift force, caused by fluidvelocity gradients; Magnus force, caused by particle spin; Basset force, which depends upon the history of the particle's motion through the fluid; Faxen force, which is a correction applied to the virtual mass effect and Basset force to account for fluid-velocity gradients; and forces caused by temperature and. density gradients.

Several other factors need to be considered when the formulas for single particle systems are generalized to describe interaction forces in realistic multiparticle systems with chemical reactions.

One, the effect of the proximity of other particles must be accounted for. This most important effect implies that the drag force is a function of the solids volume fraction, in addition to the particle Reynolds number, and must be described by formulas deduced from experimental data, as discussed in the following paragraphs.

Two, the single-particle interaction force must be corrected to account for the effect of mass transfer between the phases, as in the case of coal devolatilization or combustion, for example (Bird, Stewart, and Lightfoot 1960, p.658; Montlucon 1975).

Three, the momentum transfer accompanying such mass transfer must be included in the interaction force. 
Four, the above formulations for fluid-solids drag deal with uniform, smooth, spherical particles, whereas practical fluid-solids systems contain rough, non-spherical particles of different sizes. A narrow particle-size distribution may be characterized by an average size based on particle surface area; a broad particle-size distribution must be discretized into two or more size fractions, each characterized by an average particle size. Efforts to study the effect of nonsphericity (e.g., Leith 1987; Ganser 1993) and roughness (e.g., Crawford and Plumb 1986) on drag is ongoing, and there are no wellaccepted ways of treating such effects.

Five, it may be necessary to explicitly account for the effect of particle interactions on the fluid-solids interaction force, although equation (8) contains the implicit assumption that fluid-particle and particle-particle forces can be separated into two terms. For example, the averaging required to approximate the particles as a granular continuum renders the hydrodynamic equations incapable of resolving the wake-dominated nicrohydrodynamics near the particles that under certain favorable conditions cause the particles to form clusters. O'Brien and Syamlal (1993) argued that the effect of such aggregates must be explicitly accounted for in the fluid-solids interaction constitutive relation.

In the present work, however, we account only for the buoyancy, the drag force, and momentum transfer due to mass transfer, since those are the most significant forces and satisfactory formulations of the other effects do not exist. Thus, the fluid-solids interaction force is written as

$$
\vec{I}_{g m}=-\varepsilon_{g m} \nabla P_{g}-F_{g m}\left(\vec{v}_{g m}-\vec{v}_{g}\right)+R_{o m}\left[\xi_{o m} \vec{v}_{g m}+\bar{\xi}_{o m} \vec{v}_{g}\right] .,
$$

where the first term on right side describes the buoyancy force, the second term describes the drag force, and the third term describes the momentum transfer due to mass transfer. $R_{0 m}$ is the mass transfer from the gas phase to solids phase- $m$, where

$$
\xi_{0 \mathrm{~m}}= \begin{cases}1 & \text { for } R_{0 \mathrm{~m}}<0 \\ 0 & \text { for } R_{0 \mathrm{~m}} \geq 0\end{cases}
$$

and $\bar{\xi}_{\text {om }}=1-\xi_{\text {om }}$.

When buoyancy is included, as in equation (9), the resulting hydrodynamic equations possess imaginary characteristics, and the initial-value problems based on such equations are ill-posed. Any consistent numerical scheme for these equations is unconditionally unstable, i.e., for any constant ratio $\Delta t \Delta x$, geometrically growing instabilities will always appear if $\Delta x$ is made sufficiently small (Gidaspow 1974; Lyczkowski et al. 1978; Stewart and Wendroff 1984). Although questions about the ill-posed equations remain unsettled, ill-posed equations are widely used in practical, multiphase-flow computations (and other areas such as backward heat conduction and porous media flows) and yield usable results. Physical damping due to the momentum exchange term, numerical damping due to donor cell differencing (Stewart 1979), and the presence of a solids-stress term (Gidaspow and Ettehadieh 1983) have been suggested as mitigating effects that make such computations possible. To obtain well-posed 
equations, Bouillard et al. (1989) dropped the fluid-pressure gradient term in the solidsmomentum equation. This formulation ignores buoyancy and, therefore, is not a satisfactory model for gas-solids and liquid-solids flows. Accounting for buoyancy by writing the body force term as $\left(p_{s}-p_{z}\right) g$ is not satisfactory either, because such a term will only account for the effect of the fluid-pressure gradient caused by the body force (gravity). Therefore, such a modification of the theory is not used here, although the corresponding change in the code is minor.

Drag correlations for a single-solids phase, when generalized to multiple-solids phases, should satisfy the following condition (Syamlal 1985). A solids phase consisting of identical particles can be represented either as a single-solids phase of volume fraction $\varepsilon_{3}$ or as $M$ distinct solids phases (although of identical particle diameter and density), whose respective volume fractions $\left(\varepsilon_{\mathrm{m}}\right)$ would sum to $\varepsilon_{\mathrm{s}}$. In the former case, only one set of solids-phase momentum equations exists, whereas $M$ sets of momentum equations exist in the latter case. We require that the drag relations be generalized in such a way that the $\mathbf{M}$ momentum equations correctly sum to the single momentum equation of the former case.

Two types of experimental data can be used to develop fluid-solids drag formulas. One type, valid for high value of the solids volume fractions, is packed-bed pressure drop data expressed in the form of a correlation, such as the Ergun (1952) equation. Such a correlation must be supplemented with a drag correlation for low values of the solids volume fractions (Gidaspow 1986). The other type of data is available as correlations for the terminal velocity in fluidized or settling beds, expressed as a function of void fraction and Reynolds number (Richardson and Zaki 1954). Syamlal and O'Brien (1987) derived the following formula for converting terminal velocity correlations to drag correlations:

$$
F_{g m}=\frac{3 \varepsilon_{g m} \varepsilon_{g} \rho_{g}}{4 V_{m m}^{2} d_{p m}} C_{D s}\left(\frac{R e_{g}}{V_{g m}}\right)\left|\vec{v}_{g m}-\vec{v}_{g}\right| ;
$$

where $V_{m}$ is the terminal velocity correlation for the $m^{\text {th }}$ solids phase. $V_{m}$ can be calculated from the Richardson and Zaki (1954) correlation only numerically; an explicit formula cannot be derived. However, a closed formula for $\mathrm{V}_{\mathrm{m}}$ can be derived from a sirrilar correlation developed by Garside and Al-Dibouni (1977),

$$
V_{x m}=0.5\left(A-0.06 R e_{m}+\sqrt{\left(0.06 R e_{m}\right)^{2}+0.12 R e_{m}(2 E-A)+A^{2}}\right),
$$

where

$$
\begin{gathered}
A=\varepsilon_{g}^{4.14} \\
B=\left\{\begin{array}{ll}
0.8 \varepsilon_{g}^{1.28} & \text { if } \varepsilon_{g} \leq 0.85 \\
\varepsilon_{g}^{2.65} & \text { if } \varepsilon_{g}>0.85
\end{array},\right.
\end{gathered}
$$


and the Reynolds number of the $\mathrm{m}^{\text {th }}$ solids phase is given by

$$
R e_{\mathrm{m}}=\frac{d_{\mathrm{pm}}\left|\vec{v}_{\mathrm{gm}}-\vec{v}_{g}\right| \rho_{g}}{\mu_{g}}
$$

Here, $C_{D x}\left(R e_{m} / V_{z m}\right)$ is the single-sphere drag function. Of the numerous expressions available for $C_{D_{1}}$ (see Khan and Richardson 1987), we chose the following simple formula proposed by Dalla Valle (1948):

$$
C_{D s}(R e)=\left(0.63+\frac{4.8}{\sqrt{\operatorname{Re}}}\right)^{2}
$$

To use this formula in equation (11), note that $R e$ must be replaced with $\operatorname{Re}_{\mathrm{m}} \mathrm{V}_{\mathrm{m}}$.

\subsubsection{Solids-Solids Momentum Transfer}

Compared to fluid-solids momentum transfer, much less is known about solids-solids momentum transfer. It is safe to assume that the major effect is the drag between the phases because of velocity differences. Arastoopour, Lin, and Gidaspow (1980) observed that such a term is necessary to correctly predict segregation among particles of different sizes in a pneumatic conveyor. Arastoopour, Wang, and Weil (1982) studied this effect experimentally in a pneumatic conveyor. Equations to describe such interactions have been derived or suggested by several researchers: Soo (1967), Nakamura and Capes (1976), Syamlal (1985, 1987b), and Srinivasan and Doss (1985).

In the present work the solids-solids momentum transfer, $I_{m l}$, is represented as

$$
\vec{I}_{m 1}=-F_{m l}\left(\vec{v}_{a 1}-\vec{v}_{m m}\right)+R_{m 1}\left[\xi_{m 1} \vec{v}_{a 1}+\bar{\xi}_{m 1} \vec{v}_{m m}\right]
$$

where $R_{m l}$ is the mass transfer from solids phase- $m$ to solids phase-l,

$$
\xi_{m 1}= \begin{cases}1 & \text { for } R_{m l}<0 \\ 0 & \text { for } R_{m l} \geq 0\end{cases}
$$

and $\bar{\xi}_{m l}=1-\xi_{m l}$.

A simplified version of kinetic theory was used by Syamlal (1987b) to derive an expression for the drag coefficient $F_{\mathrm{sml}}$,

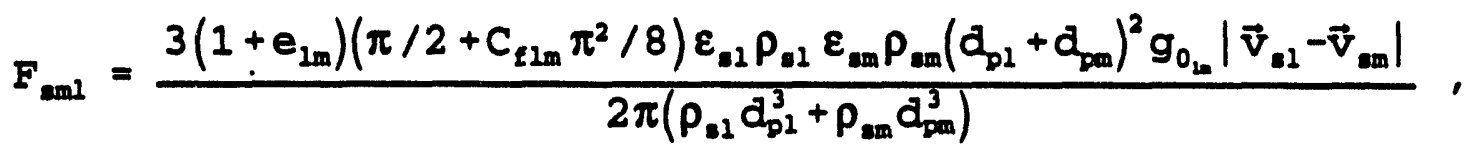


where $e_{\operatorname{lm}}$ and $C_{\operatorname{mm}}$ are the cosfficient of restitution and coefficient of friction, respectively, between the $\mathrm{I}^{\text {th }}$ and $\mathrm{m}^{\text {th }}$ solids-phase particles. The radial distribution function at contact, $g_{0_{1 m}}$, is that derived by Lebowitz (1964) for a mixture of hard spheres:



\subsubsection{Fluid-Phase Stress Tensor}

The stress tensor for the fluid phase, either gas or liquid, is given by

$$
\bar{S}_{g}=-P_{g} \bar{I}+\bar{\tau}_{g} \quad
$$

where $P_{z}$ is the pressure. The viscous stress tensor, $\bar{\tau}_{g}$, is assumed to be of the Newtonian form

$$
\bar{\tau}_{g}=2 \varepsilon_{g} \mu_{g} \bar{D}_{g}+\varepsilon_{g} \lambda_{g} \operatorname{tr}\left(\bar{D}_{g}\right) \bar{I} \quad
$$

where $\bar{I}$ is the identity tensor and $\bar{D}_{g}$ is the strain rate tensor for the fluid phase, given by

$$
\bar{D}_{g}=\frac{1}{2}\left[\nabla \vec{v}_{g}+\left(\nabla \vec{v}_{g}\right)^{x}\right] \text {. }
$$

\subsubsection{Solids-Phase Stress Tensor}

In some of the earlier studies the solids phase was assumed to be inviscid, which is a reasonable assumption for a fully fluidized bed. In such models only the hydrostatic part of the stress tensor (solids pressure) need be specified, to ensure that the void fraction does not become less than that in a packed bed. This solids pressure term was specified as an arbitrary function of void fraction that becomes very large as the void fraction approaches the packed-bed void fraction (Pritchett, Blake, and Garg 1978; Gidaspow and Ettehadieh 1983). As pointed out by Massoudi et al. (1992), the solids pressures used in various studies differ by orders of magnitude. The actual magnitude of the term itself is not of importance in the theory, so long as it prevents the void fraction from becoming unphysically small. An alternative approach, which avoids the need to specify a solids pressure function and strictly prevents the void fraction from becoming less than the packed-bed void fraction, is to treat the granular media as an incompressible fluid at a certain critical void fraction (Syamlal and O'Brien 1988). In such a formulation, a solids pressure is calculated so as to keep the void fraction from becoming less than the packed-bed void fraction. This pressure becomes zero when the void fraction becomes greater than the packed-bed void fraction. 
A more detailed description of the solids phase stresses is made possible by adopting appropriate theories proposed in the literature for describing granular flows. The unusual behavior of granular materials is well reviewed in an article by Jaeger and Nagel (1992):

"Granular materials display a variety of behaviors that are in many ways different from those of other substances. They cannot be easily classified as either solids or liquids. This has prompted the generation of analogies between the physics found in a simple sandpile and that found in complicated microscopic systems, such as flux motion in superconductors or spin glasses."

As shown in figure 2, granular flows can be classified into two distinct flow regimes: a viscous or rapidly shearing regime, in whicti stresses arise because of collisional or translational transfer of momentum, and a plastic or slowly shearing regime, in which stresses arise because of Coulomb friction between grains in enduring contact (Jenkins and Cowin 1979).

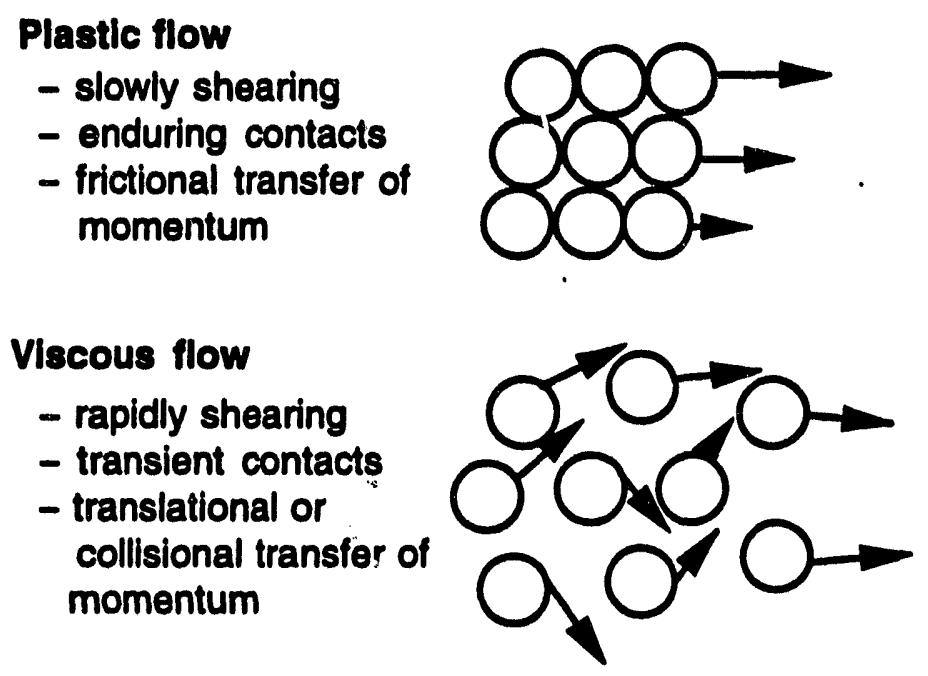

\section{Figure 2. Slowly and Rapidly Shearing Granular Flows}

Two entirely different approaches are used to describe the stresses in these flow regimes. Johnson and Jackson (1987) proposed a model to describe shearing granular flows, combining the theories of viscous and plastic flow regimes, by simply adding the two formulas. In MFIX, the theories are combined by introducing a "switch" at a critical packing, $\varepsilon_{g}{ }^{*}$, the packed-bed void fraction at which a granular flow regime transition is assumed to occur:

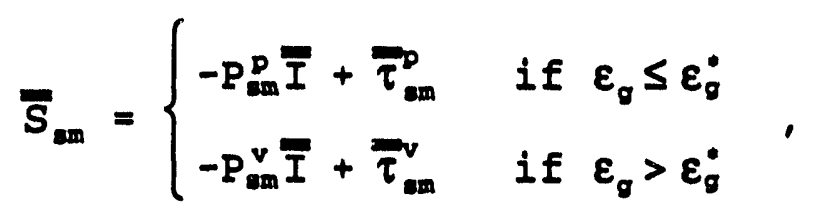

where $P_{s m}$ is the pressure and $\bar{\tau}_{g m}$ is the viscous stress in the $m^{\text {th }}$ solids phase: The superscript $\mathrm{p}$ stands for plastic regime and $\mathrm{v}$ for viscous regime. In fluidized-bed simulations, $\varepsilon_{g}^{*}$ is usually set to the void fraction at minimum fluidization. 
Stress formulations for the rapid flow regime have been reviewed in detail by Savage (1984), Jenkins (1987), Boyle and Massoudi (1989). In a pioneering work, Bagnold (1954) derived expressions for granular stress by considering the momentum transfer because of particle collisions. That approach was further extended and refined by several researchers: Ogawa, Umemura, and Oshima (1980), Shen and Ackerman (1982), and Haff (1983), to name a few. Savage and Jeffrey (1981) and Jenkins and Savage (1983) introduced the rigorous methods of the kinetic theory of gases to describe the collisional transfer of momentum and, thereby, to derive expressions for the stress tensor. The rapid flow theory is quite welldeveloped and has been extended to describe binary mixtures (Shen 1984; Farrell, Lun, and Savage 1986; Jenkins and Mancini 1987), rough particles (Lun and Savage 1987), and interstitial fluid effects (Ma and Ahmadi 1988). In rapid granular flows, the kinetic energy of mean flow first degrades into the kinetic energy of random particle fluctuations, and then dissipates as heat because of inelastic collisions. Figure 3 depicts this phenomenon and compares it to similar processes in turbulent single-phase flow. The kinetic energy of fluctuations is accounted for in the theory by a granular temperature, $\Theta_{m}$, which is different from the particle temperature (a measure of the kinetic energy of molecular vibrations within the particle). Formulas for stresses in rapid granular flows have been included in several two-phase flow models of fluidized beds and pneumatic conveyors: Syamlal (1987c), Boyle and Massoudi (1989), Sinclair and Jackson (1989), Ding and Gidaspow (1990), and Louge, Mastorakos, and Jenkins (1991).

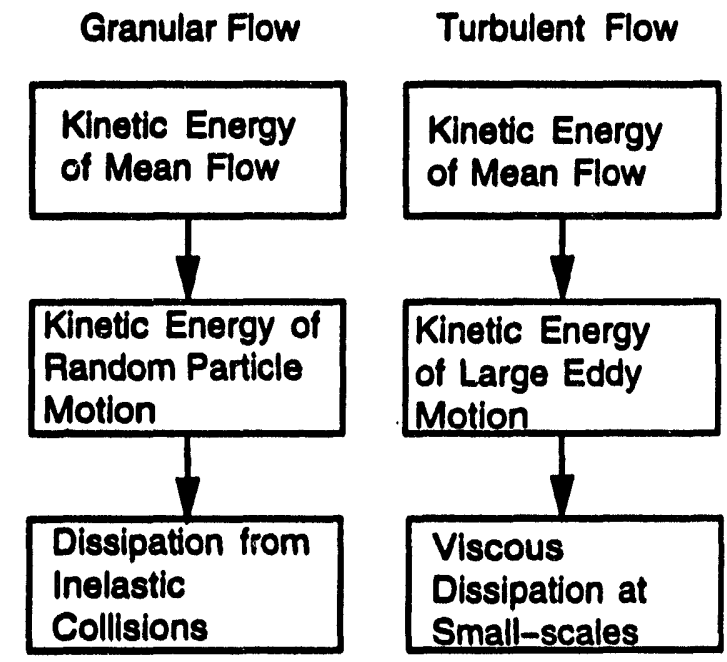

Figure 3. Energy Cascade in Granular Flows Compared With That in Turbulent Flows

The viscous stress terms in equation (24) are based on a modified form of the kinetic theory of smooth, inelastic, spherical particles developed by Lun et al. (1984). The terms accounting for momentum transfer due to particle translation (kinetic contribution) were discarded because they make the granular temperature unbounded in the dilute limit of $\varepsilon_{\mathrm{g}}$ going to one (Syamlal 1987c). In addition, we assume that the Lun et al. (1984) theory can be extended to describe stresses in multiple granular phases. The resulting expressions for stress are given below. The granular pressure is given by

$$
\mathrm{P}_{\mathrm{sm}}^{\mathrm{v}}=\mathrm{K}_{1 \mathrm{~m}} \varepsilon_{\mathrm{sm}}^{2} \Theta_{\mathrm{m}},
$$


where

$$
K_{1 m}=2\left(1+e_{\operatorname{man}}\right) \rho_{\operatorname{mim}} g_{0_{\operatorname{man}}}
$$

The granular stress is given by

$$
\bar{\tau}_{m}^{v}=2 \mu_{\mathrm{am}}^{v} \overline{\mathrm{D}}_{\mathrm{sm}}+\lambda_{\mathrm{mm}}^{v} \operatorname{tr}\left(\overline{\bar{D}}_{\mathrm{mm}}\right) \overline{\mathrm{I}} \text {. }
$$

where $\lambda_{\mathrm{sm}}^{v}$, the second coefficient of viscosity for the $\mathrm{m}^{\text {th }}$ solids phase, is given by

$$
\lambda_{\min }^{v}=K_{2 \mathrm{~m}} \varepsilon_{\min } \sqrt{\Theta_{\mathrm{m}}} \text {. }
$$

The constant $\mathrm{K}_{2 \mathrm{~m}}$ is given by

$$
K_{2 m}=\frac{4 d_{p m} \rho_{\min }\left(1+e_{m m}\right) \varepsilon_{m m} g_{0_{m m}}}{3 \sqrt{\pi}}-\frac{2}{3} K_{3 m} \text {, }
$$

and the constant $K_{3 m}$ is

$$
\begin{gathered}
K_{3 m}=\frac{d_{p m} \rho_{m m}}{2}\left\{\frac{\sqrt{\pi}}{3\left(3-e_{m m}\right)}\left[1+0.4\left(1+e_{m m}\right)\left(3 e_{m m}-1\right) \varepsilon_{m m} g_{0_{m}}\right]\right. \\
\left.+\frac{8 \varepsilon_{m m} g_{0_{m m}}\left(1+e_{m m}\right)}{5 \sqrt{\pi}}\right\} .
\end{gathered}
$$

The factor $\mu_{\mathrm{mm}}^{\mathrm{v}}$, the shear viscosity for the $\mathrm{m}^{\text {th }}$ solids phase, is given by

$$
\mu_{\mathrm{em}}^{v}=\kappa_{3 \mathrm{~m}} \varepsilon_{\mathrm{mm}} \sqrt{\theta_{\mathrm{m}}} \text {. }
$$

The strain rate tensor, $\bar{D}_{m m}$, is given by

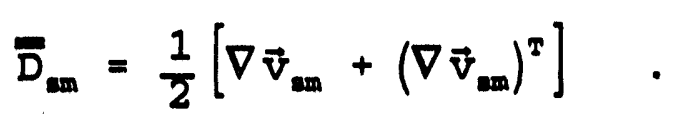

The computation of granular temperature is discussed in section 2.5.

The stresses in the plastic flow regime are usually described by adopting theories from the study of soil mechanics (Tuzun et al. 1982; Jackson 1983), although alternative theories have also been proposed (Goodman and Cowin 1972; Massoudi 1986). The stresses arise because of particle friction and are described by phenomenological models rather than mechanistic models as in the case of rapid flow regime. The soil mechanics theories use the idea of a yield function, which is a relation between the components of the stress tensor for a material about to yield, and a flow rule, which is a set of relations between the components of 
the stress and the rate of strain tensors. Jackson (1983) has described in detail the critical state theory proposed by the Cambridge School of Soil Mechanics and has shown that the theory accounts for consolidation and dilatation observed in granular flows.

Similar to the functions typically used in plastic flow theories (Jenike 1987), an arbitrary function that allows a certain amount of compressibility in the solids phase represents the solids pressure term for plastic flow regime:

$$
P^{P}=\varepsilon_{m} P^{*},
$$

where $\mathrm{P}^{*}$ is represented by an empirical power law

$$
P^{*}=A\left(\varepsilon_{g}-\varepsilon_{g}^{*}\right)^{n} \text {. }
$$

Typically, values of $A=10^{25}$ and $n=10$ have been used.

A solids stress tensor based on the critical state theory was included in MFIX with Gray and Stiles's (1988) three-dimensional generalization of a yield function proposed by Pitman and Schaeffer (1987). In that formulation, however, the solids pressure term goes to zero in the limit of zero internal friction - a condition often used in simulations to turn off the time-consuming plastic flow computations. This being unsatisfactory, a simpler formulation, proposed by Schaeffer (1987), is being used in the code now. These stresses are calculated only for solids phase-1, even when multiple solids phases are specified:

$$
\bar{\tau}_{a 1}^{p}=2 \mu_{a 1}^{p} \bar{D}_{a 1},
$$

where

$$
\mu_{s_{1}}^{p}=\frac{P^{*} \sin \phi}{2 \sqrt{I_{2 D}}} .
$$

The second invariant of the deviator of the strain rate tensor is

$$
\begin{gathered}
I_{2 D}=\frac{1}{6}\left[\left(D_{s 11}-D_{s 22}\right)^{2}+\left(D_{s 22}-D_{s 33}\right)^{2}+\left(D_{s 33}-D_{s 11}\right)^{2}\right] \\
+D_{s 12}^{2}+D_{s 23}^{2}+D_{s 31}^{2} .
\end{gathered}
$$

The viscosity values for plastic flow conditions are large. Hence, to stabilize the computation, the stress terms are calculated implicitly and an upper limit is specified for the viscosity, which becomes unbounded as $I_{2 D} \rightarrow 0$. The implicit stress calculations require a considerable amount of computational time. By setting the angle of internal friction $(\phi)$ to zero, the plastic stress computations may be turned off. Without the plastic stresses, however, the computations may predict unphysical solids circulation in packed beds.

Schaeffer (1987) and Schaeffer and Pitman (1988) conducted a linear analysis of granular flow equations that included frictional stress terms and showed that the equations may lead to violent instabilities analogous to that of the backwards heat equation. Although 
Schaefier and Pitman (1988) remind that "linear well-posedness or ill-posedness carries no rigorous implications for the nonlinear theory," we take the view that the frictional flow formulation presented here is tentative. As discussed in the previous paragraph, however, the framework required to implement such a theory exists in the code.

\subsection{Conservation of Internal Energy}

The internal energy balance for the fluid phase is written in terms of the fluid temperature:

$$
\begin{aligned}
\varepsilon_{g} \rho_{g} C_{p q}\left(\frac{\partial T_{g}}{\partial t}+\vec{v}_{g} \cdot \nabla T_{g}\right)= & -\nabla \cdot \vec{q}_{g}-H_{g 1}-H_{g 2}-\Delta H_{x q} \\
& +H_{\text {wall }}\left(T_{\text {wal1 }}-T_{q}\right),
\end{aligned}
$$

where $\vec{q}_{g}$ is the fluid-phase conductive heat flux, $\mathrm{H}_{81}$ and $\mathrm{H}_{22}$ describe fluid-solids interphase heat transfer, $\Delta \mathrm{H}_{\mathrm{rg}}$ is the heat of reaction, and the last term accounts for the heat loss to the wall. (See section 2.6.7.) The thermal energy balance for the $m=1$ solids phase is given by

$$
\varepsilon_{a 1} \rho_{a 1} C_{p=1}\left(\frac{\partial T_{a 1}}{\partial t}+\vec{v}_{a 1} \cdot \nabla T_{a 1}\right)=-\nabla \cdot \vec{q}_{a 1}+H_{g 1}-\Delta H_{x=1},
$$

where $\vec{q}_{a 1}$ is the solids-phase-1 conductive heat flux, $H_{21}$ is fluid-solids interphase heat transfer, and $\Delta \mathrm{H}_{n \mid}$ is the heat of reaction. All other solids phases are assumed to be in thermal equilibrium, to simplify the numerical solution of the energy equations. The thermal energy balance for all the other solids phases ( $m=2$ to $M$ ), in terms of an average temperature $T_{22}$, is

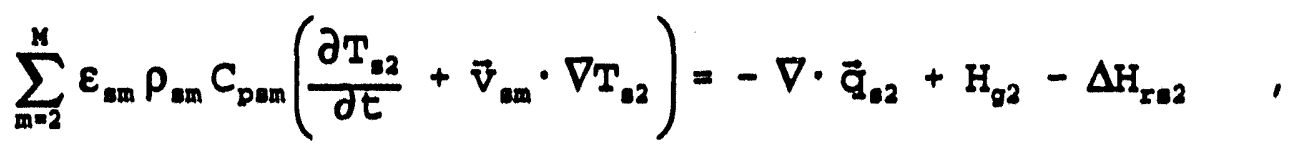

where $\vec{g}_{ \pm 2}$ is the an average solids-phase conductive heat flux, $H_{t_{2}}$ is fluid-solids interphase heat transfer, and $\Delta \mathrm{H}_{\mathrm{n} 2}$ is the heat of reaction.

A number of simplifying assumptions, none of which should be significant in typical applications to fluid-solids reactors, have been made in the formulation of thermal energy equations (38), (39), and (40):

1) The irreversible rate of increase of internal energy due to viscous dissipation has been neglected. Such terms are negligible except in the case of velocities approaching the speed of sound.

2) The reversible rate of fluid internal energy change due to compression or expansion has been neglected. Such terms will be important in transient, compressible flows. 
3) Interfacial flow work terms have not been included, which may lead to a violation of the second law (Lyczkowski, Gidaspow, and Solbrig 1982; Amold, Drew, and Lahey 1990). This does not necessarily imply large errors in the calculations, because such terms in usual MFIX applications are negligible. Furthermore, a satisfactory formulation including such terms does not exist.

4) The heat of reaction term includes both the enthalpy change due to reaction and the energy transfer because the products and reactants may be at different temperatures. (See section 2.3.4.)

5) Heat transfer between different solids phases is negligible.

6) Radiative heat transfer is not considered.

\subsubsection{Fluid-Solids Heat Transfer}

The heat transfer between the fluid and sclids is assumed to be a function of the temperature difference:

$$
H_{\text {gat }}=-\gamma_{\text {gam }}\left(T_{\text {sm }}-T_{g}\right),
$$

where $\gamma_{\mathrm{tm}}$ is the heat transfer coefficient between the fluid phase and the $\mathrm{m}^{\text {th }}$ solids phase. Since we have assumed that solids phases 2 to $M$ are in thermal equilibrium, $\gamma_{22}$ is the sum of the heat transfer coefficients $\gamma_{\mathrm{gm}}$ for $\mathrm{m}=2$ to $\mathrm{M}$. $\gamma_{\mathrm{gm}}$ is determined from the heat transfer coefficient in the absence of mass transfer, $\gamma_{\mathrm{gm}}^{0}$, corrected for interphase mass transfer by using the following formula derived from film theory (Bird, Stewart, and Lightfoot 1960, p. 658):

$$
\gamma_{g m}=\frac{C_{p g} R_{o m}}{e^{\left(C_{p g} R_{0 m} / \gamma_{g m}^{0}\right)}-1} .
$$

The heat transfer coefficient $\gamma_{\mathrm{gm}}^{0}$ is related to the particle Nusselt number $\mathrm{Nu}_{\mathrm{m}}$ :

$$
\gamma_{g m}^{0}=\frac{6 k_{g} \varepsilon_{m m} N u_{m}}{\alpha_{p m}^{2}} \text {, }
$$

where $\mathrm{Nu}_{\mathrm{m}}$ is the Nusselt number for the individual particles constituting the $\mathrm{m}^{\text {th }}$ solids phase.

The Nusselt number is typically determined from one of the many correlations reported in the literature for calculating the heat transfer between particles and fluid in packed or fluidized beds (e.g., Zabrodsky 1966; Gelperin and Einstein 1971; Gunn 1978). Syamlal and Gidaspow (1985) used a set of correlations presented by Zabrodsky (1966). Following Kuipers, Prins, and van Swaaij (1992), MFIX now uses the following correlation proposed by Gunn (1978) applicable for a porosity range of $0.35-1.0$ and a Reynolds number up to $10^{\text {s: }}$ 


$$
\begin{aligned}
N u_{m}= & \left(7-10 \varepsilon_{g}+5 \varepsilon_{g}^{2}\right)\left(1+0.7 \operatorname{Re}_{m}^{0.2} \mathrm{Pr}^{2 / 3}\right) \\
& +\left(1.33-2.4 \varepsilon_{g}+1.2 \varepsilon_{g}^{2}\right) \operatorname{Re}_{m}^{0.7} \mathrm{Pr}^{1 / 3} .
\end{aligned}
$$

The Prandtl number is defined as

$$
P r=\frac{C_{p g} \mu_{g}}{k_{g}}
$$

\subsubsection{Conductive Heat Flux in Fluid Phase}

The conductive heat flux within the fluid phase, $\vec{q}_{g}$, is described by Fourier's law:

$$
\vec{q}_{q}=-\varepsilon_{g} k_{g} \nabla T_{g}
$$

where $k_{z}$ is the gas thermal conductivity.

\subsubsection{Conductive Heat Flux in Solids Phase}

In a simulation of the heat transfer from a fluidized bed to a wall, Syamlal and Gidaspow (1985) found it necessary to consider solids-phase conductive heat flux to be able to calculate bed-to-wall heat transfer coefficients comparable to experimental measurements. The conductive heat flux in the solids phase, $\vec{g}_{a m}$, is assumed to have a form similar to that in the fluid phase:

$$
\vec{q}_{\mathrm{mm}}=-\varepsilon_{\mathrm{am}} k_{\mathrm{am}} \nabla \mathrm{T}_{\mathrm{mm}}
$$

where $k_{m m}$ is the particle phase conductivity. Since solids phases $m=2$ to $M$ are considered to be in thermal equilibrium, a sum of the flux terms is used to represent conductive fluxes in solids phase-2.

Syamlal and Gidaspow (1985) used a model due to Zehner and Schlunder (Bauer and Schlunder 1978) to determine the solids phase conductivity. Kuipers, Prins, and van Swaaij (1992) used a similar, but improved, way to determine the solids-phase conductivity. Their model accounts for direct conduction through the fractional contact area $\zeta$ and indirect conduction through a wedge of gas trapped between the particles. The model has been simplified by neglecting the radiation between the particles and the resistance to heat transfer due to inhibition of the normal movement of gas molecules between the particles (Smoluchowski effect). Following Kuipers, Prins, and van Swaaij (1992), we also delete the contribution of gas conductivity from the formulation to obtain: 


$$
\frac{k_{\mathrm{ma}}}{k_{\mathrm{g}}}=\frac{\left[\phi_{k} R_{\mathrm{km}}+\left(1-\phi_{k}\right) \lambda_{\mathrm{rm}}\right]}{\sqrt{1-\varepsilon_{\mathrm{g}}}}
$$

where

$$
\begin{aligned}
& \lambda_{x=\mathrm{m}}=-\frac{2}{\left(1-b / R_{\mathrm{km}}\right)}\left[\frac{\left(R_{\mathrm{km}}-1\right) b / R_{\mathrm{km}}}{\left(1-b / R_{\mathrm{km}}\right)^{2}} \ln \left(b / R_{\mathrm{kman}}\right)+\frac{b-1}{\left(1-b / R_{\mathrm{km}}\right)}+\frac{b+1}{2}\right] \text {, } \\
& R_{k=1}=\frac{k_{p m}}{k_{g}},
\end{aligned}
$$

and, for spherical particles,

$$
b=1.25\left(\frac{1-\varepsilon_{q}}{\varepsilon_{g}}\right)^{10 / 9}
$$

The contact area fraction has the value $\phi_{\mathrm{K}}=7.26 \times 10^{-3}$. By using this model for fluidized beds, we are clearly extending its applicability beyond the packed-bed range, where enduring contact between particles occurs. We also assume that the model can be extended to describe conduction in multiparticle systems. As a simpler alternative, $k_{\mathrm{sm}}$ can be assumed to be a small multiple of $k_{g}$, by noting that for typical values of $k_{p m}$ and the void fraction, the ratio of $k_{m m}$ to $k_{p}$ is between 1 and 5 (Syamlal and Gidaspow 1985).

\subsubsection{Heat of Reaction}

Since the energy equation is formulated in terms of the temperatures, the heat of reaction must be stated explicitly. Expressions for the heat of fluid-solids reactions must account for the difference in temperature between the phases. (See figure 4.) Let $\Delta \mathrm{H}_{0}$ be the heat of reaction at the standard temperature of $T_{0}$ for the general fluid-solids reaction

$$
a A(s)+b B(g) \rightarrow c C(s)+d D(g) \text {. }
$$




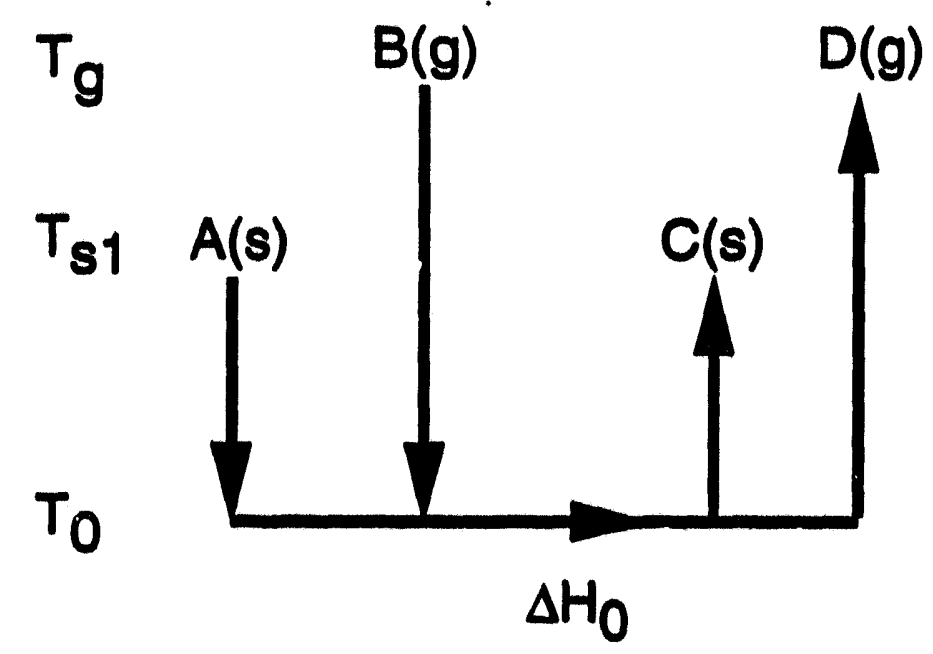

Figure 4. Computation of Heat of Reaction for Reactants at Difrerent Temperatures

Then the enthalpy change due to the reaction is

$$
\begin{aligned}
& \Delta H_{x}=a \int_{x_{01}}^{\pi_{p}} C_{p d} d T+b \int_{T_{0}}^{\pi_{p}} c_{p d} d r+\Delta H_{0} \\
& +c \int_{d_{0}}^{T_{p}} C_{p c} d T+d \int_{x_{0}}^{T_{p}} c_{p D} d T \\
& =\Delta H_{0}-\int_{d_{0}}^{T_{D}}\left(a C_{p A}-c C_{p C}\right) d T-\int_{d_{0}}^{T_{1}}\left(b C_{p B}-d C_{D D}\right) d T .
\end{aligned}
$$

In a fluid-solids reaction, the partitioning of the heat of reaction between the phases is arbitrary, since the averaging required to derive the hydrodynamic equations does not contain any information regarding the gas-solids interface. The actual chemical reactions occur in an interface region of finite dimensions. For example, in an analytical study of single-particle char gasification, Arri and Amundson (1978) showed that the hydrogen and carbon monoxide flame front may reside at the core surface, in the ash layer, or in the boundary layer surrounding the particle, depending upon process conditions. The partitioning of the heats of reaction, therefore, must be based on physical arguments. To partition the heat of the coal combustion reaction $\mathrm{C}+\mathrm{O}_{2} \rightarrow \mathrm{CO}_{2}$, for example, Syamlal and Bissett (1992) assigned the heat of reaction for the step $\mathrm{C}+1 / 2 \mathrm{O}_{2} \rightarrow \mathrm{CO}$ to the solids phase and the heat of reaction for the step $\mathrm{CO}+1 / 2 \mathrm{O}_{2} \rightarrow \mathrm{CO}_{2}$ to the gas phase. 


\subsection{Conservation of Species}

The gas and solids phases may contain an arbitrary number of chemical species, $\mathrm{N}_{\mathrm{g}}$. The species conservation equation for the gas phase is

$$
\frac{\partial}{\partial t}\left(\varepsilon_{g} \rho_{g} x_{g a}\right)+\nabla \cdot\left(\varepsilon_{g} \rho_{g} x_{g n} \vec{v}_{g}\right)=R_{g n},
$$

where $\mathrm{X}_{\mathrm{m}}$ is the mass fraction and $R_{\mathrm{pm}}$ is the rate of formation of gas species $\mathrm{n}$. The species conservation equation for solids phase $\mathrm{m}$ is



where $X_{\mathrm{tma}}$ is the mass fraction and $R_{\mathrm{gma}}$ is the rate of formation of solids phase-m, species $n$. The above equations consider the accumulation, convection, and rate of reaction but neglect the diffusive flux.

\subsubsection{Reaction Kinetics}

Reaction kinetic expressions need to be supplied to close the species balance equations. Such expressions will depend upon the specific chemistry being described. As an example, consider a coal combustion reaction,

$$
2 \mathrm{C}+\mathrm{O}_{2} \rightarrow 2 \mathrm{CO} \text {. }
$$

The most common way of determining a rate expression for this reaction is by assuming a shrinking core mechanism, as depicted in figure 5, which considers the three resistances: external film diffusion, diffusion through the ash layer, and the reaction at the surface of the unreacted core (Yoon, Wei, and Denn 1978; Wen, Chen, and Onozaki 1982). A rate expression is then derived by assuming a pseudo-steady state; that is, the time constant for the shrinking of the core is much larger than that for the transport of oxygen to the core. The rate of formation of oxygen is then given by $\left(\mathrm{O}_{2}\right.$ is gas species $1, \mathrm{CO}$ is gas species 2 , and $\mathrm{C}$ is solid species 1 )

$$
R_{\mathrm{g} 1}=R_{\mathrm{O}_{2}}=\frac{-6 \varepsilon_{\mathrm{gm}} \mathrm{P}_{\mathrm{O}_{2}}}{d_{\mathrm{gm}}\left(\frac{1}{k_{\mathrm{gm}}}+\frac{1}{k_{\mathrm{am}}}+\frac{1}{k_{\mathrm{rm}}}\right)},
$$




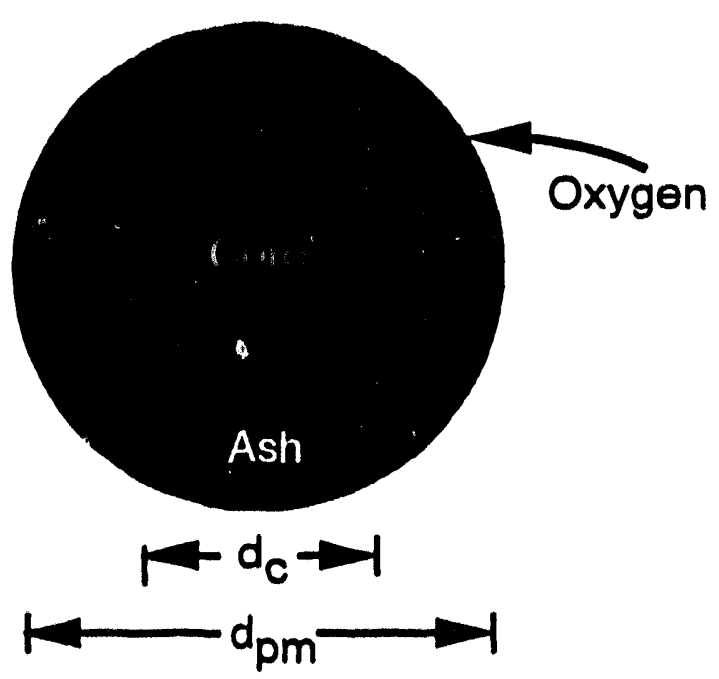

Figure 5. Shrinking Core Model for Coal Combustion

where $\mathrm{P}_{2}$ is the partial pressure of oxygen. The film resistance is given by

$$
k_{f m}=\frac{D_{\mathrm{O}_{2}} S h_{m}}{d_{p m} R_{O_{2}} T_{t m}}
$$

where $D_{\mathrm{O}_{2}}$ is the diffusion coefficient and $\mathrm{R}_{\mathrm{O}_{2}}$ is the gas constant for oxygen, $T_{\mathrm{fm}}$ is an average film temperature, and the Sherwood number [similar to equation (44) for the Nusselt number] is given by (Gunn 1978):

$$
\begin{aligned}
S h_{m}= & \left(7-10 \varepsilon_{q}+5 \varepsilon_{q}^{2}\right)\left(1+0.7 R e_{m}^{0.2} S c^{1 / 3}\right) \\
& +\left(1.33-2.4 \varepsilon_{q}+1.2 \varepsilon_{q}^{2}\right) R e_{m}^{0.7} S c^{1 / 3} .
\end{aligned}
$$

The Schmidt number is defined as

$$
S C=\frac{\mu_{g}}{\rho_{g} D_{O_{2}}}
$$

The ash layer resistance is given by

$$
k_{\mathrm{am}}=\frac{2 r_{\mathrm{dm}} D_{e}}{\left(1-r_{\mathrm{dm}}\right) a_{\mathrm{pm}} R_{\mathrm{O}_{2}} T_{\mathrm{sm}}}
$$

where $D_{e}$ is an effective ash diffusivity given by (Wen, Chen, and Onozaki 1982)

$$
D_{e}=D_{O_{2}} \varepsilon_{a s h}^{2.5}
$$


and the ratio of core diameter to particle diameter,

$$
r_{m}=\frac{d_{c}}{d_{b m}} \text {. }
$$

can be related to the solids mass fraction as

$$
r_{d m .}=\left(\frac{x_{11}^{0} x_{01}}{x_{11}^{0} x_{04}}\right)^{1 / 3},
$$

where $\mathrm{X}_{31}$ is the carbon mass fraction, $\mathrm{X}_{24}$ is the ash mass fraction, and superscript 0 indicates the initial values of those quantities. Wen et al. (1982) obtained the ash porosity from

$$
\varepsilon_{\text {anh }}=0.25+0.75\left(1-x_{a 4}^{0}\right) \text {. }
$$

The surface reaction resistance is given by (Desai and Wen 1978)

$$
k_{\mathrm{xm}}=23227 r_{\mathrm{dm}}^{2} \mathrm{e}^{\left(-27000 / 1.987 \mathrm{~T}_{\mathrm{ma}}\right)} \text {. }
$$

From equation (55), the other formation rates can be obtained as

$$
R_{g 2}=R_{c o}=-\frac{56}{32} R_{g 1}
$$

and

$$
R_{\mathrm{si}} \equiv R_{\mathrm{c}}=\frac{24}{32} R_{\mathrm{g} 1}
$$

Since this reaction occurs in the particle, the heat of reaction is assigned to the solids phase:

$$
\Delta H_{r=1}=\left[-52832-C_{D C}\left(T_{g 1}-298\right)-\left(C_{p O_{2}}-2 C_{p c 0}\right)\left(T_{g}-298\right)\right] \frac{\left|R_{g 1}\right|}{32},
$$

where the reference temperature is $298 \mathrm{~K}$.

\subsection{Conservation of Granular Energy}

Kinetic theory describing the flow of smooth, slightly inelastic, spherical particles was used in the derivation of the constitutive relation describing the stress tensor in the $\mathrm{m}^{\text {th }}$ solids phase, $\overline{\mathrm{S}}_{\mathrm{gm}}$, as presented in section 2.2.4. The resulting constitutive relations contain the quantity $\Theta_{m}$, called the "granular temperature" of the $\mathrm{m}^{\text {th }}$ solids phase. The granular temperature is proportional to the "granular energy" of the continuum, where granular energy is 
defined as the specific kinetic energy of the random fluctuating component of the particle velocity:

$$
\frac{3}{2} \theta_{m}=\frac{1}{2}\left\langle c_{m}^{2}\right\rangle
$$

where $\vec{C}_{m}$ is the fluctuating component of the instantaneous velocity $\vec{c}_{m}$ of the $m^{\text {th }}$ solids phase defined by

$$
\vec{c}_{m}=\vec{v}_{m}+\vec{C}_{m}
$$

The transport of granular energy in the $\mathrm{m}^{\text {th }}$ solids phase is governed by the relation

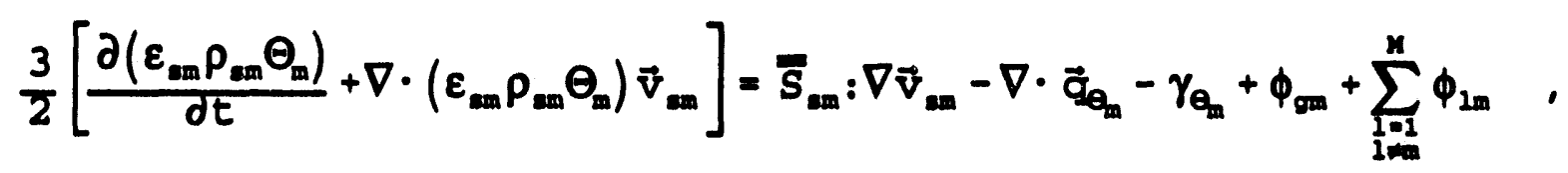

where $\gamma_{\theta_{\mathrm{m}}}$ is the rate of granular energy dissipation due to inelastic collisions, and $\mathrm{g}_{\theta_{\mathrm{m}}}$ is the diffusive flux of granular energy. The term $\phi_{\mathrm{gm}}$ accounts for the transfer of granular energy between the gas phase and the $\mathrm{m}^{\text {th }}$ solids phase, whereas $\phi_{\mathrm{Im}}$ accounts for the transfer of granular energy between the $\mathrm{m}^{\text {th }}$ and $\mathrm{l}^{\text {th }}$ solids phases. Supplying constitutive relations for equation (70) and numerically solving the $M$ coupled partial differential equations it represents is an onerous task.

This task is simplified in this work by first deriving a single partial differential equation (PDE) that represents the transport of the granular kinetic energy of the mixture of all solids phases. This "mixture granular energy equation" is formed by summing the individual PDEs of equation (70)

$$
\begin{aligned}
& \frac{3}{2} \frac{\partial}{\partial t} \sum_{m=1}^{M} \varepsilon_{m m} \rho_{s m} \Theta_{m}+\frac{3}{2} \nabla \cdot \sum_{m=1}^{M} \varepsilon_{m m} \rho_{m} \theta_{m} \vec{v}_{m} \\
& =\sum_{m=1}^{n}\left[\bar{S}_{m m}: \nabla \vec{v}_{m}-\nabla \cdot \vec{q}_{\theta_{m}}-\gamma_{\theta_{m}}+\phi_{g m}+\sum_{\substack{i=1 \\
1, m}}^{M} \phi_{1 m}\right]
\end{aligned}
$$

Now define a mixture granular temperature

$$
\Theta=\frac{\sum_{m=1}^{n}\left(\dot{\varepsilon}_{\mathrm{sm}} \rho_{\mathrm{mm}} \theta_{m}\right)}{\sum_{m=1}^{n}\left(\varepsilon_{\mathrm{mm}} \rho_{\mathrm{sm}}\right)}
$$


and a mixture density

$$
\rho_{0}=\sum_{m=1}^{X} \varepsilon_{\operatorname{mam}} \rho_{\mathrm{am}}
$$

Therefore,

$$
\sum_{m=1}^{n} \varepsilon_{m=m} \rho_{m} \theta_{m}=\rho_{1} \theta
$$

Assume equipartition of granular energy, i.e.,

$$
m_{p m} \theta_{m}=m_{p 1} \theta_{1}
$$

where $m_{p m}$ is the mass of the particles that constitute solids phase $m$. Now, eliminating the mass of the particles in favor of density and diameter and summing equation (75) over sub. script 1 yields

$$
\rho_{\mathrm{sm}} \theta_{\mathrm{m}}=\frac{\rho_{\mathrm{s}} \theta}{d_{\mathrm{pm}}^{3} \sum_{1=1}^{n}\left(\varepsilon_{\mathrm{s} 1} / d_{p 1}^{3}\right)}
$$

Then

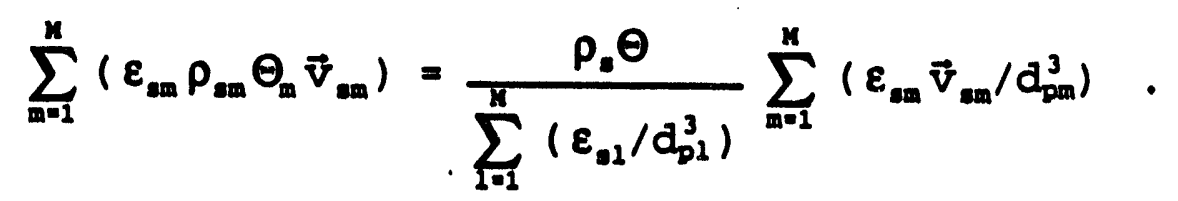

Let an average velocity be given by

$$
\vec{v}_{1}=\frac{\sum_{m=1}^{n}\left(\varepsilon_{\mathrm{am}} \vec{v}_{\mathrm{am}} / d_{\mathrm{pm}}^{3}\right)}{\sum_{1=1}^{n}\left(\varepsilon_{\mathrm{s}} / d_{p 1}^{3}\right)},
$$

so that

$$
\sum_{m=1}^{n} \varepsilon_{\mathrm{em}} \rho_{\mathrm{gm}} \Theta_{\mathrm{m}} \vec{v}_{\mathrm{gm}}=\rho_{\mathrm{g}} \Theta \vec{v}_{\mathrm{g}}
$$

Then the averaged granular energy equation becomes 


$$
\begin{aligned}
& \frac{3}{2} \cdot \frac{\partial}{\partial t} \rho_{s} \Theta+\frac{3}{2} \nabla \cdot \rho_{8} \Theta \vec{v}_{s} \\
& =\Sigma\left[\bar{s}_{\mathrm{mm}}: \nabla \vec{v}_{\mathrm{mm}}-\nabla \cdot{\overrightarrow{g_{\theta}}}_{\theta_{m}}-\gamma_{\theta_{m}}+\phi_{g \mathrm{~m}}+\sum_{\mathrm{m}=1}^{n} \phi_{2 \mathrm{~m}}\right] .
\end{aligned}
$$

After $\Theta$ is determined by solving equation (80), values of $\Theta_{\mathrm{m}}$ are obtained from

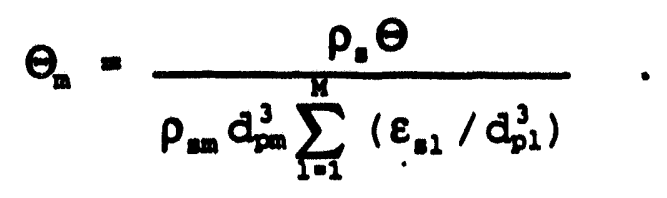

The implementation of the detailed granular energy equation described above in MFIX is still under development. The current version of the code uses an algebraic expression for granular temperature, $\Theta_{m}$, obtained from the energy equation of Lun et al. (1984), by assuming that the granular energy is dissipated locally; neglecting the convection and diffusion contributions; and retaining only the generation and dissipation terms (Syamlal 1987c). The resulting algebraic granular energy equation is

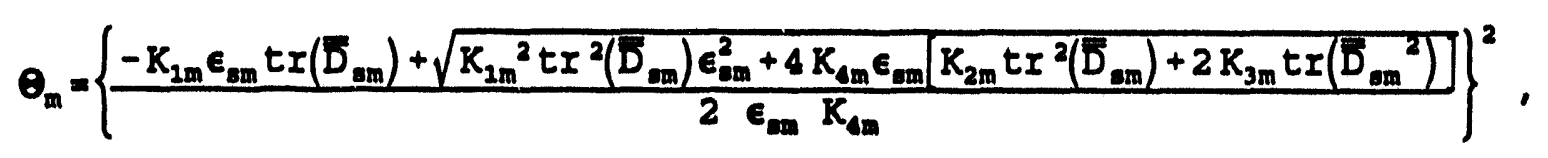

where $\mathrm{K}_{4 \mathrm{~m}}$ is given by

$$
K_{d m}=\frac{12\left(1-e_{m m}^{2}\right) \rho_{\mathrm{gm}} g_{\mathrm{omm}_{m}}}{d_{\mathrm{pm}} \sqrt{\pi}}
$$

\subsubsection{Diffusive Flux of Granular Energy}

The granular energy equation for the $\mathrm{m}^{\text {th }}$ solids phase, equation (70), contains the term $\vec{q}_{\theta_{m}}$ describing the diffusive flux of granular energy,

$$
\vec{q}_{\theta_{m}}=-k_{\theta_{m}} \nabla \theta_{m}
$$

As in the case of $\bar{S}_{\operatorname{man}}$ (section 2.2.4), the kinetic contribution in Lun et al. (1984) theory has been deleted. In addition, the term in the collisional contribution to $\vec{q}_{\theta_{\mathrm{m}}}$ that is proportional to $\nabla \epsilon_{\mathrm{am}}$ was neglected. The diffusion coefficient for granular energy, $\mathrm{k}_{\boldsymbol{\theta}_{\mathrm{m}}}$, is described by 


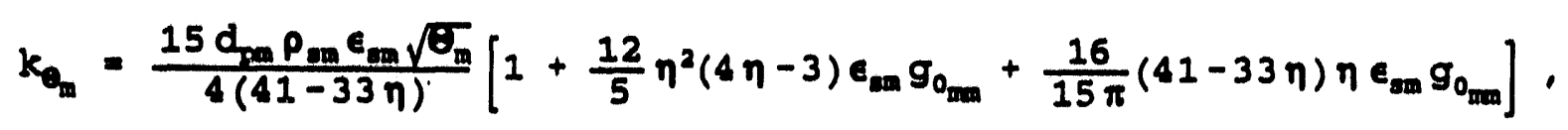

where

$$
\eta=\frac{1}{2}\left(1+\theta_{\operatorname{man}}\right)
$$

\subsubsection{Granular Energy Dissipation}

The term $\gamma_{\Theta_{m}}$ represents the rate of granular energy dissipation within the $m^{\text {th }}$ solids phase due to collisions between the particles constituting the continuum. This term is represented by the expression derived by Lun and others (1984),

$$
\gamma_{Q_{m}}=K_{\operatorname{sm}} \epsilon_{\sin }^{2} \theta_{m}^{\frac{3}{2}}
$$

where $K_{4 m}$ has already been defined in equation (83).

\subsubsection{Granular Energy Transfer}

The term $\phi_{\mathrm{em}}$ accounts for the transfer of granular energy between the fluid phase and the solids phase. Physically, this represents the transfer to the fluid phase of the kinetic energy of random fluctuations in particle velocity. An expression for this transfer is given by Ding and Gidaspow (1990):

$$
\phi_{g \mathrm{~m}}=-3 \mathrm{~F}_{\mathrm{gm}} \Theta_{\mathrm{m}}
$$

The term $\phi_{\operatorname{lm}}$ in the granular energy equation accounts for the transfer of granular energy between the $\mathrm{m}^{\text {th }}$ and $\mathrm{l}^{\text {th }}$ solids phase continua due to collisions between their respective particles. This contribution is ignored in this work:

$$
\phi_{1 m}=0 \text {. }
$$

\subsection{Initial and Boundary Conditions}

\subsubsection{Initial Conditions}

The initial values of all field variables $\left(\varepsilon, P_{g}, T_{g}, T_{s 1}, T_{s 2}, \vec{v}_{g}, \vec{v}_{s}, X_{g n}, X_{3 m a}\right)$ must be specified for the entire computational domain. However, the initial transients are usually not of interest, and the solution is governed by the boundary conditions. In that case the initial conditions need only be accurate enough to allow convergence. In fluidized beds, for example, the solids velocity is usually set to zero, and the gas velocity is given some uniform unidirectional value. 


\subsubsection{Inflow Boundary}

An inflow boundary condition should be specified at a location where uniform flow is expected. All the field variables need to be specified at the boundary. Two types of inflow boundary conditions are possible, constant pressure or constant mass flux. The constant mass flux condition is more commonly used.

\subsubsection{Outflow Boundary}

Specified constant pressure is the most common condition for the fluid outflow boundary. MFIX also allows the user to specify constant velocity at outflow boundaries. This condition should be used only when another constant pressure outflow condition has been specified and the specified outflow is much less than that expected from the constant pressure outflow boundary.

\subsubsection{Impermeable Walls}

At internal or external impermeable walls, the normal velocities are set to zero. The condition for the tangential components is specified either as a no-slip or as a free-slip condition. These boundary conditions are imposed with the heip of fictitious boundary cells. The no-slip condition is specified as

$$
\left(v_{g}\right)_{\text {E1Ct1tious co11 }}=-\left(v_{g}\right)_{\text {col1 next to wa11 }},
$$

so that the velocity at the wall is zero. The free-slip condition is specified as

$$
\left(v_{g}\right)_{\text {s1etitious col1 }}=\left(v_{g}\right)_{\text {cel1 next to wa11 }},
$$

so that the gradient of the velocity at the wall is zero.

\subsubsection{Impermeable and Semipermeable Internal Surfaces}

MFIX allows the user to specify internal surfaces, which are infinitesimally thin walls or porous surfaces in the flow domain, exerting no tangential stresses (free-slip). At an impermeable internal surface, the normal gas and solids velocity are set to zero. At a semipermeable internal surface, the solids velocity is given a user-specified fixed value. The gas velocity is allowed to vary, and the flow resistance offered by the porous media is calculated from the formula

$$
f_{g x}=-\frac{\mu_{g}}{C_{1}} u_{g}-\frac{1}{2} C_{2} \rho_{g}\left|u_{g}\right| u_{g},
$$

using the $\mathrm{x}$-component as an example. 


\subsubsection{Cyclic Boundaries}

Cyclic boundary conditions are automatically specified for the $\theta$ direction in cylindrical coordinates. Rotationally (without pressure drop) or translationally (with pressure drop) cyclic boundary conditions may be specified at any of the boundaries.

\subsubsection{Wall Heat Transfer}

The wall heat transfer in a fluidized bed can be predicted by using a sufficiently fine grid near the walls (Syamlal and Gidaspow 1985). This approach, however, is too expensive for practical computations. Therefore, the boundary conditions for the energy equations in MFIX are set such that the walls are non-conducting, and the term $\mathrm{H}_{\text {wall }}\left(\mathrm{T}_{\text {wall }}-\mathrm{T}_{8}\right)$ is provided to account for wall heat loss. $H_{\text {wall }}$ and $T_{\text {wall }}$ are user-defined functions of space and time that allow the user to specify complex heat loss characteristics.

\subsubsection{Boundary Conditions for Granular Energy Equation}

At the present time no boundary condition is required for the granular energy equation because the algebraic form of the equation is solved. 


\section{Summary of Governing Equations and Constitutive Relations}

The equations that are solved in the current version of MFIX are summarized in this section.

Gas continuity:

$$
\frac{\partial}{\partial E}\left(\varepsilon_{g} \rho_{g}\right)+\nabla \cdot\left(\varepsilon_{g} P_{g} \vec{v}_{g}\right)=\sum_{n=1}^{N g} R_{g n}
$$

Solids continuity:

$$
\frac{\partial}{\partial t}\left(\varepsilon_{a m} P_{m a m}\right)+\nabla \cdot\left(\varepsilon_{a m} P_{a m} \vec{\nabla}_{m m}\right)=\sum_{n=1}^{M} R_{m a n}
$$

Gas momentum balance:

$$
\begin{aligned}
\frac{\partial}{\partial E}\left(\varepsilon_{g} \rho_{g} \vec{v}_{g}\right)+\nabla \cdot\left(\varepsilon_{g} \rho_{g} \vec{v}_{g} \vec{v}_{g}\right)= & -\varepsilon_{g} \nabla P_{g}+\nabla \cdot \bar{\tau}_{g}+\sum_{m=1}^{M} F_{g m}\left(\vec{v}_{a m}-\vec{v}_{g}\right)+\vec{f}_{g} \\
& +\varepsilon_{g} P_{g} \vec{g}-\sum_{m=1}^{X} R_{o m}\left[\xi_{o m} \vec{v}_{a m}+\vec{\xi}_{o m} \vec{v}_{g}\right]
\end{aligned}
$$

Solids momentum balance:

$$
\begin{aligned}
& \frac{\partial}{\partial E}\left(\varepsilon_{\mathrm{am}} \rho_{\mathrm{am}} \vec{v}_{\mathrm{am}}\right)+\nabla \cdot\left(\varepsilon_{\mathrm{am}} \rho_{\mathrm{am}} \vec{v}_{\mathrm{am}} \vec{v}_{\mathrm{am}}\right)=-\varepsilon_{\mathrm{am}} \nabla P_{\mathrm{g}}+\nabla \cdot \bar{S}_{\mathrm{am}} \\
& -F_{g m}\left(\vec{\nabla}_{a m}-\vec{v}_{g}\right)+\sum_{1=1}^{M} F_{a l m}\left(\vec{v}_{a 1}-\vec{\nabla}_{a m}\right) \\
& +\varepsilon_{a m} \rho_{s m} \vec{g}-\sum_{1=0}^{n} R_{m 1}\left[\xi_{m 1} \vec{v}_{a 1}+\bar{\xi}_{m 1} \vec{v}_{a m}\right]
\end{aligned}
$$


Gas energy balance:

$$
\begin{aligned}
& \varepsilon_{g} \rho_{g} C_{D Q}\left(\frac{\partial T_{q}}{\partial E}+\nabla_{g} \cdot \nabla T_{g}\right)=-\nabla \cdot q_{q}+\gamma_{g 1}\left(T_{g 1}-T_{q g}\right)+\gamma_{g 2}\left(T_{g 2}-T_{g}\right)-\Delta H_{g q} \\
& +H_{\text {ma11 }}\left(T_{\operatorname{ma11}}-T_{g}\right)
\end{aligned}
$$

Solids - 1 energy balance:

$$
\varepsilon_{a 1} P_{a 1} C_{p e 1}\left(\frac{\partial T_{a 1}}{\partial t}+\nabla_{a 1} \cdot \nabla T_{a 1}\right)=-\nabla \cdot \vec{q}_{11}-\gamma_{g 1}\left(T_{a 1}-T_{q}\right)-\Delta H_{z a 1}
$$

Solids - 2 energy balance:

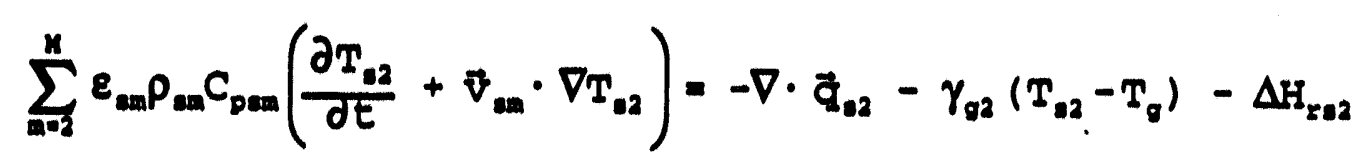

Gas species balance:

$$
\frac{\partial}{\partial E}\left(\varepsilon_{g} \rho_{g} X_{g n}\right)+\nabla \cdot\left(\varepsilon_{g} \rho_{g} X_{g n} \vec{\nabla}_{g}\right)=R_{g m}
$$

Solids species balance:

$$
\frac{\partial}{\partial t}\left(\varepsilon_{\operatorname{mam}} P_{\operatorname{sm}} X_{\operatorname{man}}\right)+\nabla \cdot\left(\varepsilon_{\operatorname{sm}} P_{\operatorname{sm}} X_{\operatorname{man}} \vec{\nabla}_{g m}\right)=R_{g m n}
$$

Gas-solids drag:

$$
F_{g m}=\frac{3 \varepsilon_{\mathrm{gm}} \varepsilon_{\mathrm{g}} \rho_{\mathrm{g}}}{4 V_{\mathrm{rm}}^{2} d_{\mathrm{pm}}}\left(0.63+4.8 \sqrt{V_{\mathrm{gm}} / R e_{\mathrm{m}}}\right)^{2}\left|\vec{v}_{\mathrm{gm}}-\vec{v}_{\mathrm{g}}\right|
$$




$$
V_{x m}=0.5\left(A-0.06 R e_{m}+\sqrt{\left(0.06 R e_{m}\right)^{2}+0.12 R e_{m}(2 B-A)+A^{2}}\right)
$$

$$
A=\varepsilon_{0}^{4 \cdot 10}
$$

$$
B= \begin{cases}0.8 \varepsilon_{q}^{1.28} & \text { if } \varepsilon_{g} \leq 0.85 \\ \varepsilon_{q}^{2.08} & \text { if } \varepsilon_{g}>0.85\end{cases}
$$

$$
R \epsilon_{m}=\frac{d_{p m}\left|\nabla_{2 m}-\nabla_{g}\right| \rho_{g}}{\mu_{g}}
$$

Solids-solids drag:

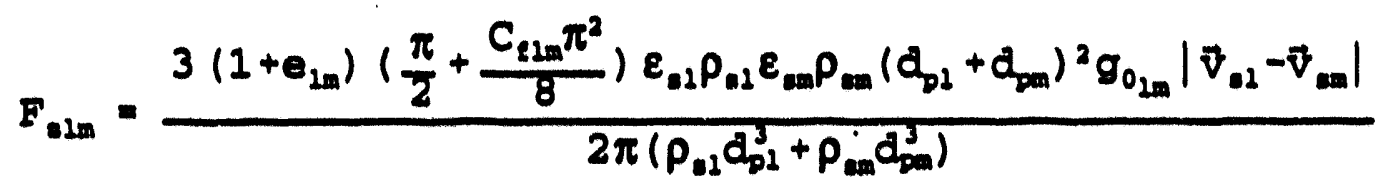

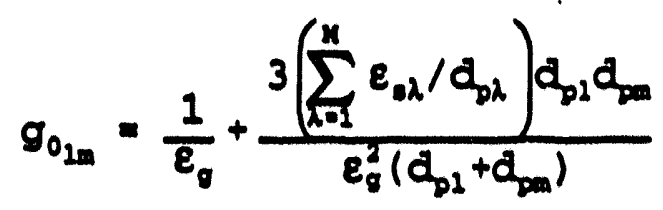

Gas-phase stress:

$$
\bar{\tau}_{\sigma}=2 \varepsilon_{g} \mu_{\sigma} \bar{D}_{\sigma}-\frac{2}{3} \varepsilon_{g} \mu_{g} \operatorname{tr}\left(\bar{D}_{\sigma}\right) \bar{I}
$$

Note that $\bar{\tau}_{\sigma}$ is set to zero in the current version (1.70) of MFIX. 
Granular stress:

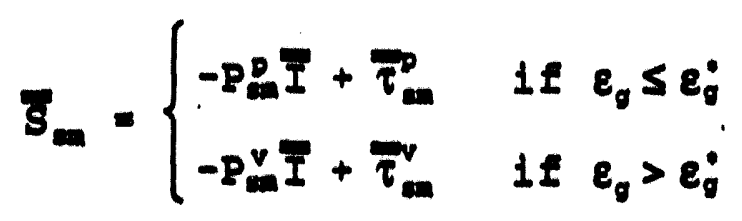

Plastlc regime:

$$
\begin{aligned}
& P R=\varepsilon_{m} P^{*} \\
& P^{\cdot}=10^{25}\left(\varepsilon_{g}-\varepsilon_{g}^{j}\right)^{10} \\
& \tau_{a d}^{p}=2 \mu_{01}^{p} \bar{D} \\
& \mu_{11}^{p}=\frac{P^{\cdot} \sin \phi}{2 \sqrt{I_{2 D}}} \\
& I_{2 D}=\frac{1}{6}\left(\left(D_{a 12}-D_{a 22}\right)^{2}+\left(D_{e 22}-D_{a 33}\right)^{2}+\left(D_{a 33}-D_{a 12}\right)^{2}\right) \\
& +D_{a 12}^{2}+D_{a 23}^{2}+D_{031}^{2}
\end{aligned}
$$

Viscous regime:

$$
\begin{gathered}
P_{\mathrm{gm}}^{v}=K_{1 \mathrm{~m}} \varepsilon_{\mathrm{sm}}^{2} \Theta_{\mathrm{m}} \\
\bar{\tau}_{\mathrm{gm}}^{v}=\lambda_{\mathrm{sm}}^{v} \operatorname{tr}\left(\overline{D_{\mathrm{am}}}\right) \bar{I}+2 \mu_{\mathrm{sm}}^{v} \bar{D}_{\mathrm{am}}
\end{gathered}
$$




$$
\begin{aligned}
& \lambda_{\mathrm{mim}}^{v}=\mathrm{K}_{2 \mathrm{~m}} \varepsilon_{m \mathrm{~m}} \sqrt{\theta_{\mathrm{m}}} \\
& \mu_{m}^{v}=K_{3 m} \varepsilon_{m} \sqrt{\theta_{m}} \\
& K_{2 m}=2\left(1+\theta_{m m}\right) P_{z m} g_{0_{m}} \\
& K_{2 m}=4 d_{b m} P_{a m}\left(1+\theta_{m m}\right) \varepsilon_{m a m} g_{0_{m m}} /(3 \sqrt{\pi})-\frac{2}{3} K_{3 m} \\
& \dot{k}_{3 m}=\frac{d_{p m} p_{m=m}}{2}\left\{\frac{\sqrt{\pi}}{3\left(3-\theta_{m}\right)}\left[1+0.4\left(1+e_{m}\right)\left(3 e_{m}-1\right) \varepsilon_{m m} g_{0_{m}}\right]\right. \\
& \left.+\frac{8 \varepsilon_{m m} g_{0 m}\left(1+e_{m m}\right)}{5 \sqrt{\pi}}\right\} \\
& \sigma_{0-m}=\frac{1}{\varepsilon_{g}}+\frac{3 d_{p \operatorname{man}}}{2 \varepsilon_{g}^{2}} \sum_{\lambda=1}^{n} \frac{\varepsilon_{a \lambda}}{d_{p \lambda}}
\end{aligned}
$$

Gas-sollds heat transfer:

$$
\begin{aligned}
& \gamma_{o m}=\frac{C_{p g} R_{0 m}}{e^{\left(C_{p g} R_{0 m} / \gamma_{g m}^{0 m}\right)}-1} . \\
& \gamma_{\mathrm{gm}}^{0}=\frac{6 \mathrm{k}_{\mathrm{g}} \varepsilon_{\mathrm{mam}} N u_{\mathrm{m}}}{d_{\mathrm{pm}}^{2}},
\end{aligned}
$$




$$
\begin{aligned}
N u_{m}= & \left(7-10 \varepsilon_{g}+5 \varepsilon_{g}^{2}\right)\left(1+0.7 \operatorname{Re}_{m}^{0.2} \mathrm{Pr}^{1 / 3}\right) \\
& +\left(1.33-2.4 \varepsilon_{g}+1.2 \varepsilon_{g}^{2}\right) \operatorname{Re}_{m}^{0.7} \mathrm{Pr}^{1 / 3}
\end{aligned}
$$

Granular energy equation:

$$
\theta_{m}=\left\{\frac{-K_{2 m} e_{m m} t r\left(D_{m m}\right)+\sqrt{K_{1 m}^{2} t I^{2}\left(D_{c m}\right) \epsilon_{m}^{2}+4 K_{d m} e_{m m}\left[K_{2 m} t I^{2}\left(D_{m m}\right)+2 K_{3 m} t r\left(D_{m m}^{2}\right)\right]}}{2 \varepsilon_{m m} K_{t m}}\right\}^{2} \quad \text { (127) }
$$

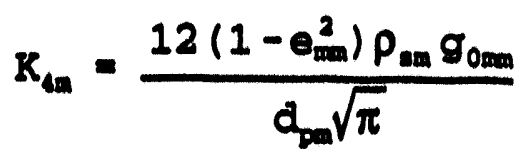

(128)

36. 


\section{References}

Anderson, T.B., and Jackson, R., 1967, "A Fluid Mechanical Description of Fluidized Beds," I\&EC Fundam., 6, 527-534.

Arastoopour, H., Lin, D., and Gidaspow, D., 1980, "Hydrodynamic Analysis of Pneumatic Transport of a Mixture of Two Particle Sizes," Multiphase Transport, Ed. Veziroglu, T.N., Hemisphere Publishing Corporation, 4, 1853-1871.

Arastoopour, H., Wang, C.-H., and Weil, S.A., 1982, "Particle-Particle Interaction Force in a Dilute Gas-Solid System," Chem. Eng. Sci, 37, 1379-1384.

Arnold, G.S., Drew, D.A., and Lahey, R.T. Jr., 1990, "An Assessment of Multiphase Flow Models Using the Second Law of Thermodynamics," Int. J. Multiphase Flow, 16, 481-494.

Arri, L.E., and Amundson, N.R., 1978, "An Analytical Study of Single Particle Char Gasification," AJChE J., 24, 72-87.

Bagnold, R.A., 1954, "Experiments on a Gravity-Free Dispersion of Large Solid Spheres in a Newtonian Fluid Under Shear," Proc. R. Soc., London, A225, 49-63.

Bauer, R., and Schlunder, E.U., 1978, "Effective Radial Thermal Conductivity of Packings in Gas Flow: Part II: Thermal Conductivity of the Packing Fraction Without Gas Flow," Int. Chem. Eng., 18, 189-204.

Bedford, A., and Drumheller, D.S., 1983, "Recent Advances: Theories of Immiscible and Structured Mixtures," Int. J. Eng. Sci., 21, 863-960.

Bird, R.B., Stewart, W.E., and Lightfoot, E.N., 1960, Transport Phenomena, John Wiley \& Sons, New York.

Blake, T.R., and Chen, P.R., 1981, "Computer Modeling of Fluidized Bed Coal Gasification Reactors," Am. Chem. Soc. Symp. Ser., 168, 157-183.

Bouillard, J.X., Lyczkowski, R.W., Folga, S., Gidaspow, D., and Berry, G.F., 1989, "Hydrodynamics of Erosion of Heat Exchanger Tubes in Fluidized Bed Combustors," Can. J. Chem. Eng., 67, 218-229.

Boyle, E.J., and Massoudi, M., 1989, "Kinetic Theories oi Granular Materials with Applications to Fluidized Beds," Technical Note, DOE/METC-89/4088, NTIS/DE89000977, National Technical Information Service, Springfield, VA.

Bowen, R.M., 1976, "Theory of Mixtures," Continuum Physics, Ed. Eringen, A.C., 3, 1-127. 
Burge, S.W., 1991, "FORCE2 - A Multidimensional Flow Program for Gas Solids Flow: Vol. I, User's Guide; Vol II, Theory Guide," Report No. RDD:91:4911-10-01:01\&02, Babcock \& Wilcox, Alliance, $\mathrm{OH}$.

Crawford, C.W., and Plumb, O.A., 1986, "The Influence of Surface Roughness on Resistance to Flow Through Packed Beds," J. Fluids Eng., 108, 343-347.

Dalla Valle, J.M., 1948, Micromeritics, Pitman, London.

Davidson, J.F., 1961, Symposium on Fluidization - Discussion, Trans. Inst. Chem. Eng., 39, 230-232.

Davidson J.F., and Harrison, D., 1963, Fluidized Particles, Cambridge: The University Press, London.

Desai, P.R., and Wen, C.Y., 1978, "Computer Modeling of the MERC Fixed Bed Gasifier," MERC/CR-78/3, Morgantown Energy Technology Center, Morgantown, WV.

Ding, J., and Gidaspow, D., 1990, "A Bubbling Fluidization Model Using Kinetic Theory of Granular Flow," AIChE J., 36, 523-538.

Drew, D.A., and Segel, L.A., 1971, "Averaged Equations of Two-Phase Flow," Stud. Appl. Math., L, 205-231.

Ergun, S., 1952, "Fluid Flow Through Packed Columns," Chem. Eng. Prog., 48, 89-94.

Farrell, M., Lun, C.K.K., and Savage, S.B., 1986, "A Simple Kinetic Theory for Granular Flow of Binary Mixtures of Smooth, Inelastic, Spherical Particles," Acta Mechanica, 63, 45-60.

Ganser, G.H., 1993, "A Rational Approach to Drag Prediction of Spherical and Nonspherical Particles," Powder Tech., 77, 143-152.

Garg, S.K., and Pritchett, J.W., 1975, "Dynamics of Gas-Fluidized Beds," J. Appl. Phys., 46, 4493-4500.

Garside, J., and Al-Dibouni, M.R., 1977, "Velocity-Voidage Relationships for Fluidization and Sedimentation," I\&EC Proc. Des. Dev., 16, 206-214.

Gelperin, N.I., and Einstein, V.G., 1971, "Heat Transfer in Fluidized Beds," Fluidization, Academic Press, New York, 471-540.

Gidaspow, D., 1974, Round Table Discussion (RT-1-2). Modeling of Two-Phase Flow. 5th International Heat Transfer Conference, Tokyo. 
Gidaspow, D., and Ettahadieh, B., 1983, "Fluidization in Two-Dimensional Beds with a Jet; 2. Hydrodynamic Modeling," I\&EC Fundam., 22, 193-201.

Gidaspow, D., Syamlal, M., Austing, J.L., Tulis, A.J., Sumida, W.K., and Comeyne, W., 1984, "The Large-Scale Detonation of a Particulate Pyrotechnic in a Computer-Modeled Dispersed State," Proceedings of the Ninth International Pyrotechnics Seminar, IIT Research Institute, Chicago, II, 193.

Gidaspow, D., 1986, "Hydrodynamics of Fluidization and Heat Transfer: Supercomputer Modeling," Appl. Mech. Rev., 39, 1-23.

Goodman, M.A. and Cowin, S.C., 1972, "A Continuum Theory for Granular Materials," Arch. Rational Mech. Anal., 44, 249-266.

Gray, D:D., and Stiles, J.M., 1988, "On the Constitutive Relation for Frictional Flow of Granular Materials," Topical Report, DOE/MC/21353-2584, NTIS/DE88001089, National Technical Information Service, Springfield, VA.

Gunn, D.J., 1978, "Transfer of Heat or Mass to Particles in Fixed and Fluidized Beds," Int. J. Heat Mass Transfer, 21, 467-476.

Haff, P.K., 1983, "Grain Flow as a Fluid Mechanical Phenomenon," J. Fluid Mech., 134, 401-430.

Harlow, F.H., and Amsden, A.A., 1975, "Numerical Calculation of Multiphase Fluid Flow," J. Comp. Physics, 17, 19-52.

Ishii, M., 1975, Thermo-Fluid Dynamic Theory of Fluid-Particle Systems, Eyrolles, Paris.

Jackson, R., 1963, "The Mechanics of Fluidized Beds: Part I: The Stability of the State of Uniform Fluidization," Trans. Inst. Chem. Eng., 41, 13-21.

Jackson, R., 1970, "The Present Status of Fluid Mechanical Theories of Fluidization," Fluidization Fundamentals and Application, Chemical Engineering Progress, AIChE Symposium Series, 66, No. 105, 3-13.

Jackson, R., 1983, "Some Mathematical and Physical Aspects of Continuum Models for the Motion of Granular Materials," in Theory of Dispersed Multiphase Flow Ed. R.E. Meyer, Academic Press, New York.

Jaeger, H.M., and Nagel, S.R., 1992, "Physics of the Granular State," Science, 255, 15231531.

Jenike, A.W., 1987, "A Theory of Flow of Particulate Solids in Converging and Diverging Channels Based on a Conical Yield Function," Powder Tech., 50, 229-236. 
Jenkins, J.T., and Cowin, S.C., 1979, "Theories for Flowing Granular Materials," Mech. Applied to Transport of Bulk Materials, Ap. Mech. Div. of ASME, 31, 79-89.

Jenkins, J.T., and Savage, S.B., 1983, "A Theory for the Rapid Flow of Identical, Smooth, Nearly Elastic, Spherical Particles," J. Fluid Mech.; 130; 187-202.

Jenkins, J.T., 1987, "Rapid Flows of Granular Materials," in Non-Classical Continuum Mechanics, Eds. Knops, R., and Lacey, A., Cambridge University Press, 213-225.

Jenkins, J.T., and Mancini, F., 1987, "Balance Laws and Constitutive Relations for Plane Flows of a Dense, Binary, Mixture of Smooth, Nearly Elastic, Circular Disks," J. Appl. Mech., 54, 27-34.

Johnson, G., Massoudi, M., and Rajagopal, K.R., 1990, "A Review of Interaction Mechanisms in Fluid-Solid Flows," DOE/PETC/TR-90/9, NTIS/DE91000941, National Technical Information Service, Springfield, VA.

Johnson, P.C., and Jackson, R., 1987, "Frictional-Collisional Constitutive Relations for Granular Materials with Application to Plane Shearing," J. Fluid Mech., 176, 67-93.

Joseph, D.D. and Lundgren, T.S., 1990, "Ensemble Averaged and Mixture Theory Equations for Incompressible Fluid-Particle Suspensions, Int. J. Multiphase Flow, 16, 35-42.

Khan, A.R., and Richardson, J.F., 1987, "The Resistance to Motion of a Solid Sphere in a Fluid," Chem. Eng. Comm., 62, 135-150.

Krambeck, F.J., Avidan, A.A., Lee, C.K., and Lo, M.N., 1987, "Predicting Fluid-Bed Reactor Efficiency Using Adsorbing Gas Tracers," AIChE J., 33, 1727-1734.

Kuipers, J.A.M., Prins, W., and van Swaaij, W.P.M., 1992, "Numerical Calculation of Wallto-Bed Heat-Transfer Coefficients in Gas-Fluidized Beds," AIChE J., 38, 1079-1091.

Kuipers, J.A.M., van Duin, K.J., van Beckum, F.P.H., van Swaaij, W.P.M., 1993, "Computer Simulation of the Hydrodynamics of a Two-Dimensional Gas-Fluidized Bed," Computers Chem. Eng., 17, 839-858.

Lebowitz, J.L., 1964, "Exact Solution of Generalized Percus-Yevick Equation for a Mixture of Hard Spheres," Phys. Rev., A133, 895-899.

Leith, D., 1987, "Drag on Nonspherical Objects," Aerosol Sci. Technol., 6, 153-161.

Louge, M.Y., Mastorakos, E., and Jenkins, J.T., 1991, "The Role of Particle Collisions in Pneumatic Transport," J. Fluid Mech., 231, 345-359. 
Lun, C.K.K., Savage, S.B., Jeffrey, D.J., and Chepurniy, N., 1984, "Kinetic Theories for Granular Flow: Inelastic Particles in Couette Flow and Slightly Inelastic Particles in a General Flow Field," J. Fluid Mech., 140, 223-256.

Lun, C.K.K., and Savage, S.B., 1987, "A Simple Kinetic Theory for Granular Flow of Rough, Inelastic, Spherical Particles," J. Appl. Mech., 54, 47-53.

Lyczkowski, R.W., Gidaspow, D., Solbrig, C.W., and Hughes, E.C., 1978, "Characteristics and Stability Analyses of Transient One-Dimensional Two-Phase Equations and Their Finite Difference Approximations," Nucl. Sci. Eng., 66, 378-396.

Lyczkowski, R.W., Gidaspow, D., and Solbrig, C.W., 1982, "Multiphase Flow - Models for Nuclear, Fossil, and Biomass Energy Production," Chapter in Advances in Transport Processes, Eds. Majumdar, A., and Mashelkar, R., Wiley-Eastern, New York, 198-351.

Lyczkowski, R.W., and Bouillard, J.X., 1989, "Interim User's Manual for FLUFIX/MOD1: A Computer Program for Fluid-Solids Hydrodynamics," Argonne National Laboratory, Report ANL/EES-TM-361, Argonne, II.

Ma, D., and Ahmadi, G., 1988, "A Kinetic Model for Rapid Granular Flows of Nearly Elastic Particles Including Interstitial Fluid Effects," Powder Technology, 56, 191-207.

Massoudi, M., 1986, Application of Mixture Theory to Fluidized Beds, Ph. D. Thesis, University of Pittsburgh, Pittsburgh, PA.

Massoudi, M., Rajagopal, K.R., Ekmann, J.M., and Mathur, M.P., 1992, "Remarks on the Modeling of Fluidized Systems," AIChE J., 38, 471-472.

Montlucon, J., 1975, "Heat and Mass Transfer in the Vicinity of an Evaporating Droplet," Int. J. Multiphase Flow, 2, 171-182.

Murray, J.D., 1965, "On the Mathematics of Fluidization Part 1. Fundamental Equations and Wave Propagation," J. Fluid Mech., 21, 465-493.

Nakamura, K., and Capes, C.E., 1976, "Vertical Pneumatic Conveying of Binary Particle Mixtures," Fluidization Technology, Ed. Keairns, D.L., Hemisphere Publishing Corp., Washington, DC, 159-184.

O'Brien, T.J., and Syamlal, M., 1990, "NIMPF: A Nonisothermal Multiparticle Fluidized-Bed Hydrodynamic Model," in Numerical Methods for Multiphase Flows, Eds. Celik, I., Hughes, D., Crowe, C.T., and Lankford, D., FED-Vol. 91, ASME, New York, 65-72.

O’Brien, T.J., and Syamlal, M., 1991, "Fossil Fuel Circulating Fluidized Bed: Simulation and Experiment," in Advances in Fluidized Systems, Eds. Gaden, E.L., Weimer, A.W., AIChE Symposium Series No. 281, 87, 127-136. 
O'Brien, T.J. and Syamlal, M., 1993, "Particle Cluster Effects in the Numerical Simulation of a Circulating Fluidized Bed," presented at the 4th International CFB Conference, Somerset, PA, August 1-5.

Ogawa, S.; Umemura, A., and Oshima, N., 1980, "On the Equations of Fully Fluidized Granular Materials," ZAMP, 31, 483-493.

Passman, S.L., Nunziato, J.W., and Walsh, E.K., 1983, "A Theory of Multiphase Mixtures," Technical Report, Sandia National Laboratory, SAND 82-2261.

Pigford, R.L., and Baron, T., 1965, "Hydrodynamic Stability of a Fluidized Bed," I\&EC, 4, 81-87.

Pitman, B., and Schaeffer, D., 1987, "Stability of Time Dependent Compressible Granular Flow in Two Dimensions," Comm. Pure Appl. Math., 40, 421-447.

Pritchett, J.W., Blake, T.R., and Garg, S.K., 1978, "A Numerical Model of Gas Fluidized Beds," AlChE Symp. Series No. 176, 74, 134-148.

'Richardson, J.F., and Zaki, W.N., 1954, "Sedimentation and Fluidization: Part I," Trans. Inst. Chem. Eng., 32, 35-53.

Richner, D.W., Minoura, T., Pritchett, J.W., and Blake, T.R., 1990, "Computer Simulation of Isothermal Fluidization in Large-scale Laboratory Rigs," AIChE J., 36, 361-369.

Rivard, W. C., and Torrey, M.D., 1977, "K-FIX: A Computer Program for Transient, TwoDimensional, Two-Fluid Flow," LA-NUREG-6623.

Rogers, W.A., and Boyle, E.J., 1991, "Prediction of Wear in a Fluidized Bed," Technical Note, DOE/METC-92/4110, NTIS/DE92001265, National Technical Information Service, Springfield, VA.

Ruckenstein, E., and Tzeculescu, M., 1967, "On the Hydrodynamics of the Fluidized Bed," In International Symposium on Fluidization, Eindhoven, Ed., A.A.M. Drinkhenburg, Netherlands University Press, 180-188.

Savage, S.B., 1984, "The Mechanics of Rapid Granular Flows," in Advances in Applied Mechanics, 24, Academic Press Inc., New York, 289-366.

Savage, S.B., and Jeffrey, D.J., 1981, "The Stress Tensor in a Granular Flow at High Shear Rates," J. Fluid Mech., 110, 255-272.

Schaeffer, D.G., 1987, "Instability in the Evolution Equations Describing Incompressible Granular Flow," J. Diff. Eq., 66, 19-50. 
Schaeffer, D.G., and Pitman, E.B., 1988, "Ill-Posedness in Three-Dimensional Plastic Flow," Comm. Pure Appl. Math., 41, 879-890.

Scharff, M.F., Chan, R.K.C., Chiou, M.J., Dietrich, D.T., Dion, D.D., Klein, H.H., Laird, D.N., Levine, H.R., Meister, C.A., and Srinivas, B., 1982, "Computer Modeling of Mixing and Agglomeration in Coal Conversion Reactors, Vol. I \& II," DOE/ET/10329-1211.

Schneyer, G.P., Peterson, E.W., Chen, P.J., Brownell, D.H., and Blake, T.R., 1981, "Computer Modeling of Coal Gasification Reactors," Final Report for June 1975-1980, DOE/ET/10247.

Shen, H.H., and Ackerman, N.L., 1982, "Constitutive Relationships for Fluid-Solid Mixtures," J. Eng. Mech. Div., Proc. of ASCE, 108, 748-763.

Shen, H.H., 1984, "Stresses in a Rapid Flow of Spherical Solid with Two Sizes," in Particulate Science and Technology, 2, Hemisphere Publishing Corp., New York, 37-56.

Shi, Y.T., Gidaspow, D., and Wasan, D., 1987, "Hydrodynamics of Electrofluidization: Separation of Pyrites from Coal," AIChE J., 33, 1322-1333.

Sinclair, J.L., and Jackson, R., 1989, "Gas-Particle Flow in a Vertical Pipe with ParticleParticle Interactions," AIChE J., 35, 1473-1486.

Soo, S.L., 1967, Fluid Dynamics of Multiphase Systems, Blaisdell Publishing Corp., Waltham, MA.

Squires, A.M., Kwauk, M., and Avidan, A.A., 1985, "Fluid Beds: At Last, Challenging Two Entrenched Practices," Science, 230, 1329-1337.

Srinivasan, M.G., and Doss, E.D., 1985, "Momentum Transfer Due to Particle-Particle Interaction in Dilute Gas-Solid Flows," Chem. Eng. Sci., 40, 1791-1792.

Stewart, H.B., 1979, "Stability of Two-Phase Flow Calculation Using Two-Fluid Models," J. Comput. Phys., 33, 259-270.

Stewart, H.B., and Wendroff, B., 1984, "Two-Phase Flow: Models and Methods," J. Comput. Phys., 56, 363-409.

Syamlal, M., 1985, Multiphase Hydrodynamics of Gas-Solids Flow, Ph.D. Dissertation, Illinois Institute of Technology.

Syamlal, M., 1987a, "NIMPF: A Computer Code for Nonisothermal Multiparticle Fluidization," unpublished EG\&G report. 
Syamlal, M., 1987b, "The Particle-Particle Drag Term in a Multiparticle Model of Fluidization," Topical Report, DOE/MC/21353-2373, NTIS/DE87006500, National Technical Information Service, Springfield, VA.

Syamlal, M., 1987c, "A Review of Granular Stress Constitutive Relations," Topical Report, DOE/MC/21353-2372, NTIS/DE87006499, National Technical Information Service, Springfield, VA.

Syamlal, M., and Bissett, L.A., 1992, "METC Gasifier Advanced Simulation (MGAS) Model," Technical Note, DOE/METC-92/4108, NTIS/DE92001111, National Technical Information Service, Springfield, VA.

Syamlal, M., and Gidaspow, D., 1985, "Hydrodynamics of Fluidization: Prediction of Wall to Bed Heat Transfer Coefficients," AIChE J., 31, 127-135.

Syamlal, M., and O'Brien, T.J., 1987, "A Generalized Drag Correlation for Multiparticle Systems," Unpublished report.

Syamlal, M., and O'Brien, T.J., 1988, "Simulation of Granular Layer Inversion in Liquid Fluidized Beds," Int. J. Multiphase Flow, 14, 473-481.

Syamlal, M., and O'Brien, T.J., 1989, "Computer Simulation of Bubbles in a Fluidized Bed," in Fluidization and Fluid Particle Systems: Fundamentals and Applications, Ed. L.-S. Fan, AIChE Symposium Series No. 270, 85, 22-31.

Tuzun, U., Houlsby, G.T., Nedderman, R.M., and Savage, S.B., 1982, "The Flow of Granular Materials-II, Velocity Distributions in Slow Flow," Chem. Eng. Sci., 37, 1691-1789.

Wen, C.Y., Chen, H., and Onozaki, M., 1982, "User's Manual for Computer Simulation and Design of the Moving Bed Coal Gasifier," DOE/MC/16474-1390, NTIS/DE83009533, National Technical Information Service, Springfield, VA.

Yoon, H., Wei, J., and Denn, M.M., 1978, "A Model for Moving-Bed Coal Gasification Reactors," AIChE J., 24, 885-903.

Zabrodsky, S.S., 1966, Hydrodynamics and Heat Transfer in Fluidized Beds, The M.I.T. Press, Cambridge, MA. 


\section{Nomenclature}

A - Function of void fraction defined by Eq. (13)

b - Function of void fraction defined by Eq. (51)

B - Function of void fraction defined by Eq. (14)

$C_{D_{1}} \quad-\quad$ Single particle drag function'

$\mathrm{C}_{\mathrm{pg}} \quad$ - Specific heat of the fluid phase; $\mathrm{J} /(\mathrm{kg} \cdot \mathrm{K})$

$\mathrm{C}_{\mathrm{nm}} \quad$ - Coefficient of friction for solids phases 1 and $\mathrm{m}$.

$\mathrm{C}_{\mathrm{pum}} \quad-\quad$ Specific heat of the $\mathrm{m}^{\text {th }}$ solids phase; $\mathrm{J} /(\mathrm{kg} \cdot \mathrm{K})$

$d_{p m} \quad-\quad$ Diameter of the particles constituting the $m^{\text {th }}$ solids phase; $m$

$D_{02} \quad-\quad$ Oxygen diffusivity; $\mathrm{m}^{2} / \mathrm{s}$

$\bar{D}_{\mathrm{g}} \quad-\quad$ Rate of strain tensor, fluid phase, Eq. (23); $\mathrm{s}^{-1}$

$\bar{D}_{\mathrm{mam}} \quad-\quad$ Rate of strain tensor, solids phase-m; $\mathrm{s}^{-1}$

$e_{\mathrm{Im}} \quad$ - Coefficient of restitution for the collisions of $\mathrm{m}^{\text {th }}$ and $\mathrm{l}^{\text {th }}$ solids phases

$\overrightarrow{\mathrm{f}}_{\mathrm{g}} \quad$ - Fluid flow resistance due to porous media; $\mathrm{N} / \mathrm{m}^{3}$

$\mathrm{F}_{\mathrm{gm}} \quad$ - Coefficient for the interphase force between the fluid phase and the $\mathrm{m}^{\text {th }}$ solids phase; $\mathrm{kg} /\left(\mathrm{m}^{3} \mathrm{~s}\right)$

$F_{\mathrm{stm}} \quad$ - Coefficient for the interphase force between the $\mathrm{l}^{\text {th }}$ solids phase and the $\mathrm{m}^{\text {th }}$ solids phase; $\mathrm{kg} /\left(\mathrm{m}^{3} \mathrm{~s}\right)$

$\vec{g} \quad$ - Azceleration due to gravity; $\mathrm{m} / \mathrm{s}^{2}$

$g_{0_{1 m}} \quad-\quad$ Radial distribution function at contact

$\mathrm{H}_{\mathrm{gl}} \quad$ - Heat transfer from fluid to solids phase- $1 ; \mathrm{J} /\left(\mathrm{m}^{3} \mathrm{~s}\right)$

$\mathrm{H}_{\mathrm{g} 2}$ - Heat transfer from fluid to solids phases-2 to $\mathrm{M} ; \mathrm{J} /\left(\mathrm{m}^{3} \mathrm{~s}\right)$

$\Delta \mathrm{H}_{\mathrm{n}} \quad$ - Heat of reaction in the fluid phase; $\mathrm{J} /\left(\mathrm{m}^{3} \mathrm{~s}\right)$ 
$\Delta \mathrm{H}_{\mathrm{nm}} \quad$ - Heat of reaction in the $\mathrm{m}^{\mathrm{th}}$ solids phase; $\mathrm{J} /\left(\mathrm{m}^{3} \mathrm{~s}\right)$

$\mathrm{H}_{\text {well }} \quad$ - Wall heat transfer coefficient; $\mathrm{J} /\left(\mathrm{m}^{3} \cdot \mathrm{K} \cdot \mathrm{s}\right)$

$I_{2 D}$ - Second invariant of the deviator of the strain rate tensor for solids phase-1, Eq. (37); $8^{-2}$

$I_{\mathrm{m}}$. . Momentum transfer from fluid phase to $\mathrm{m}^{\text {th }}$ solids phase; $\mathrm{N} / \mathrm{m}^{3}$

Im - Momentum transfer from $\mathrm{m}^{\text {th }}$ to $\mathrm{I}^{\text {th }}$ solids phases; $\mathrm{N} / \mathrm{m}^{3}$

$k_{\text {mm }} \quad$ - Ash layer resistance; $s / m$

$k_{\text {tm }} \quad$ - Film resistance; $s / m$

k - Fluid phase conductivity; $\mathrm{J} /(\mathrm{m} \cdot \mathrm{K} \cdot \mathrm{s})$

$k_{\mathrm{pm}} \quad$ - Conductivity of material that constitutes solids phase- $\mathrm{m} ; \mathrm{J} /(\mathrm{m} \cdot \mathrm{K} \cdot \mathrm{s})$

$k_{\mathrm{m}} \quad$ - Surface reaction resistance; $\mathrm{s} / \mathrm{m}$.

$k_{2 m} \quad-\quad$ Solids phase-m conductivity; $\mathrm{J} /(\mathrm{m} \cdot \mathrm{K} \cdot \mathrm{s})$

$k_{Q_{\mathrm{m}}} \quad-\quad$ Granular energy conductivity; $\mathrm{Js} / \mathrm{m}^{3}$

$\mathrm{K}_{\mathrm{Im}} \quad$ - Granular stress constant defined by Eq. (26); $\mathrm{kg} / \mathrm{m}^{3}$

$\mathrm{K}_{2 \mathrm{~m}} \quad$ - Granular stress constant defined by Eq. (29); $\mathrm{kg} / \mathrm{m}^{2}$

$\mathrm{K}_{3 \mathrm{~m}} \quad$ - Granular stress constant defined by Eq. (30); $\mathrm{kg} / \mathrm{m}^{2}$

$\mathrm{K}_{4 \mathrm{~m}} \quad-\quad$ Granular stress constant defined by Eq. (83); $\mathrm{kg} / \mathrm{m}^{4}$

1 - Index of the $\mathbb{I}^{\text {th }}$ solids phase; also used as a miscellaneous index

m - Index of the $m^{\text {th }}$ solids phase. $" m=0$ " indicates fluid phase

M - Total number of solids phases

Mw - Average molecular weight of gas

n - Index of the $\mathrm{n}^{\text {th }}$ chemical species

$\mathrm{N}_{8} \quad-\quad$ Total number of fluid phase chemical species

$\mathrm{N}_{\mathrm{sm}} \quad-\quad$ Total number of solids phase-m chemical species 
$\mathrm{Nu}_{\mathrm{m}} \quad$ - Nusselt number

$\mathrm{P}_{8} \quad$ - Pressure in the fluid phase; $\mathrm{Pa}$

Po2 - Partial pressure of oxygen; $\mathrm{Pa}$

PD - Pressure in Solids phase-m, plastic regime; $\mathbf{P a}$

Pะ - Pressure in Solids phase- $m$, viscous regime; $\mathrm{Pa}$

$\mathrm{P}^{*} \quad$ - Total solids pressure in plastic regime; $\mathrm{Pa}$

Pr - Prandtl number, Eq. (45)

a. - Fluid-phase conductive heat flux; $J /\left(\mathrm{m}^{2} \mathrm{~s}\right)$

q.1 - Solids-phase-1 conductive heat flux; $J /\left(m^{2} s\right)$

¿.2 - Solids-phase-2 to $M$ conductive heat flux; $J /\left(m^{2} s\right)$

$\tilde{q}_{\theta_{\mathrm{w}}} \quad$ - Diffusive flux of granular energy; $J /\left(\mathrm{m}^{2} \mathrm{~s}\right)$

$r_{d m} \quad$ Ratio of core diameter to particle diameter

R - Universal gas constant; $\mathrm{Pam} /(\mathrm{kmol} \cdot \mathrm{K})$

$\mathrm{Re}_{\mathrm{m}} \quad-\quad \mathrm{m}^{\text {th }}$ solids phase particle Reynolds number, Eq. (15)

$R_{\mathrm{km}} \quad$ - Ratio of solids to fluid conductivity, Eq. (50)

$R_{\mathrm{ml}} \quad$ - Rate of transfer of mass from $\mathrm{m}^{\text {th }}$ phase to $\mathrm{l}^{\text {th }}$ phase. 1 or $\mathrm{m}=0$ indicates fluid phase; $\mathrm{kg} /\left(\mathrm{m}^{3} \mathrm{~s}\right)$

$R_{\mathrm{za}} \quad$ - Rate of production of the $\mathrm{n}^{\text {th }}$ chemical species in the fluid phase; $\mathrm{kg} /\left(\mathrm{m}^{3} \mathrm{~s}\right)$

$R_{\text {man }} \quad$ - Rate of production of the $n^{\text {th }}$ chemical species in the $m^{\text {th }}$ solids phase; $\left(\mathrm{kg} / \mathrm{m}^{3} \mathrm{~s}\right)$

Sc . . Schmidt number, Eq. (58)

$\overline{\mathrm{S}}_{\mathrm{g}} \quad$ - $\quad$ Fluid phase stress tensor; $\mathrm{Pa}$

$\mathrm{Sh}_{\mathrm{m}} \quad$ - Sherwood number

$\overline{\mathrm{s}}_{\mathrm{mm}} \quad-\quad$ Solids phase-m stress tensor; $\mathrm{Pa}$ 
Time; $\mathrm{s}$

$\mathbf{T}_{8} \quad$ - Thermodynamic temperature of the fluid phase; $\mathbf{K}$

$T_{11} \quad$ - Thermodynamic temperature of the solids phase no. $1 ; K$

$\mathbf{T}_{12} \quad$ - Average thermodynamic temperature of the solids phases, $m=2, \ldots, M ; K$

$\mathbf{T}_{\text {wall }} \quad$ - Wall temperature; $\mathbf{K}$

17. Fluid phase velocity vector; $\mathrm{m} / \mathrm{s}$

$\nabla_{m} \quad-\quad m^{\text {th }}$ solids phase velocity vector; $\mathrm{m} / \mathrm{s}$

$V_{m} \quad$ - The ratio of the terminal velocity of a group of particles to that of an isolated particle

$\mathrm{X}_{\mathrm{m}} \quad$ - Mass fraction of the $\mathrm{n}^{\text {th }}$ chemical species in the fluid phase

$\mathrm{X}_{\mathrm{ame}} \quad$ - Mass fraction of the $\mathrm{n}^{\text {th }}$ chemical species in the $\mathrm{m}^{\text {th }}$ solids phase

\section{GREEK LETTERS}

$\gamma_{\mathrm{em}} \quad$ - Fluid-solids heat transfer coefficient corrected for interphase mass transfer; $\mathrm{J} /\left(\mathrm{m}^{3} \cdot \mathrm{K} \cdot \mathrm{s}\right)$

$\gamma_{\mathrm{gm}}^{0} \quad$ - Fluid-solids heat transfer coefficient not corrected for interphase mass transfer; $\mathrm{J} /\left(\mathrm{m}^{3} \cdot \mathrm{K} s\right)$

$\gamma_{\theta_{\mathrm{m}}} \quad-\quad$ Granular energy dissipation due to inelastic collisions; $\mathrm{J} / \mathrm{m}^{3} \mathrm{~s}$

8 - Volume fraction of the fluid phase (void fraction)

$\varepsilon_{0}^{:} \quad$ - Packed-bed (minimum) void fraction

$\varepsilon_{\mathrm{mm}} \quad$ Volume fraction of the $\mathrm{m}^{\text {th }}$ solids phase

$\eta \quad$ - Function of restitution coefficient, Eq. (86)

$\theta_{\mathrm{m}} \quad-\quad$ Granular temperature of phase-m; $\mathrm{m}^{2} / \mathrm{s}^{2}$

$\lambda_{\operatorname{mm}} \quad$ - Solids conductivity function defined by Eq. (49)

$\lambda_{\mathrm{mal}}^{v} \quad-\quad$ Second coefficient of solids viscosity, viscous regime; $\mathrm{kg} /(\mathrm{ms})$

$\mu_{8} \quad$ - Molecular viscosity of the fluid phase; $\mathrm{kg} /(\mathrm{m} \cdot \mathrm{s})$ 
$\mu_{B_{1}}^{p} \quad-\quad$ Solids viscosity, plastic regime; $\mathrm{kg} /(\mathrm{ms})$

$\mu_{01}^{v} \quad$ - Solids viscosity, viscous regime; $\mathrm{kg} /(\mathrm{m} \cdot \mathrm{s})$

$\xi_{\text {mal }} \quad-\quad \xi_{m 1}=1$ if $R_{m l}<0$; else $\xi_{m 1}=0$.

P. - Microscopic (material) density of the fluid phase; $\mathrm{kg} / \mathrm{m}^{3}$

$\rho_{\sigma}^{\prime} \quad-\quad$ Macroscopic (effective) density of the fluid phase, Eq.(2); $\mathrm{kg} / \mathrm{m}^{3}$

$P_{\mathrm{am}} \quad$ - . Microscopic (material) density of the $\mathrm{m}^{\text {th }}$ solids phase; $\mathrm{kg} / \mathrm{m}^{3}$

Pam - Macroscopic (bulk) density of the $\mathrm{m}^{\text {th }}$ solids phase, Eq. (3); $\mathrm{kg} / \mathrm{m}^{3}$

$\bar{\tau}$ - Fluid phase deviatoric stress tensor; $\mathrm{Pa}$

$\tau_{\text {am }} \quad$ - Solids phase-m deviatoric stress tensor, plastic regime; $\mathrm{Pa}$

$\bar{\tau}_{\text {ma }}^{v} \quad-\quad$ Solids phase-m deviatoric stress tensor, viscous regime; $\mathrm{Pa}$

$\phi \quad$ - Angle of internal friction

$\phi_{\mathrm{gm}} \quad$ - Granular energy transfer to fluid phase; $\mathrm{J} /\left(\mathrm{m}^{3} \mathrm{~s}\right)$

$\phi_{\operatorname{lm}} \quad$ - Granular energy transfer between solids phases; $\mathrm{J} /\left(\mathrm{m}^{3} \mathrm{~s}\right)$

\$k - Contact area fraction in solids conductivity model 

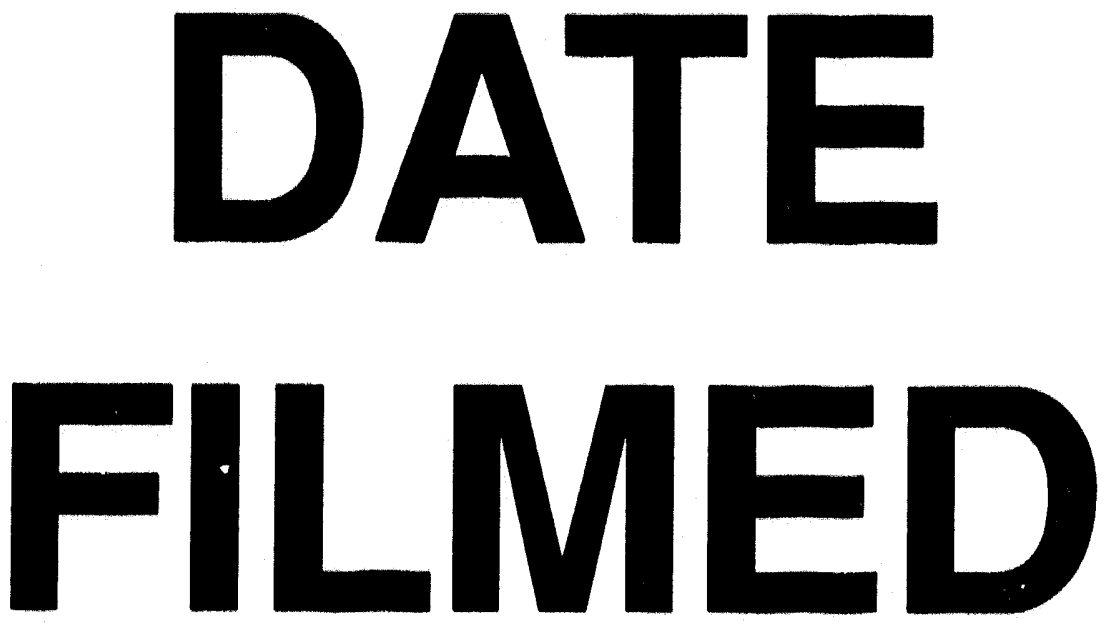

$6 / 2 / 94$
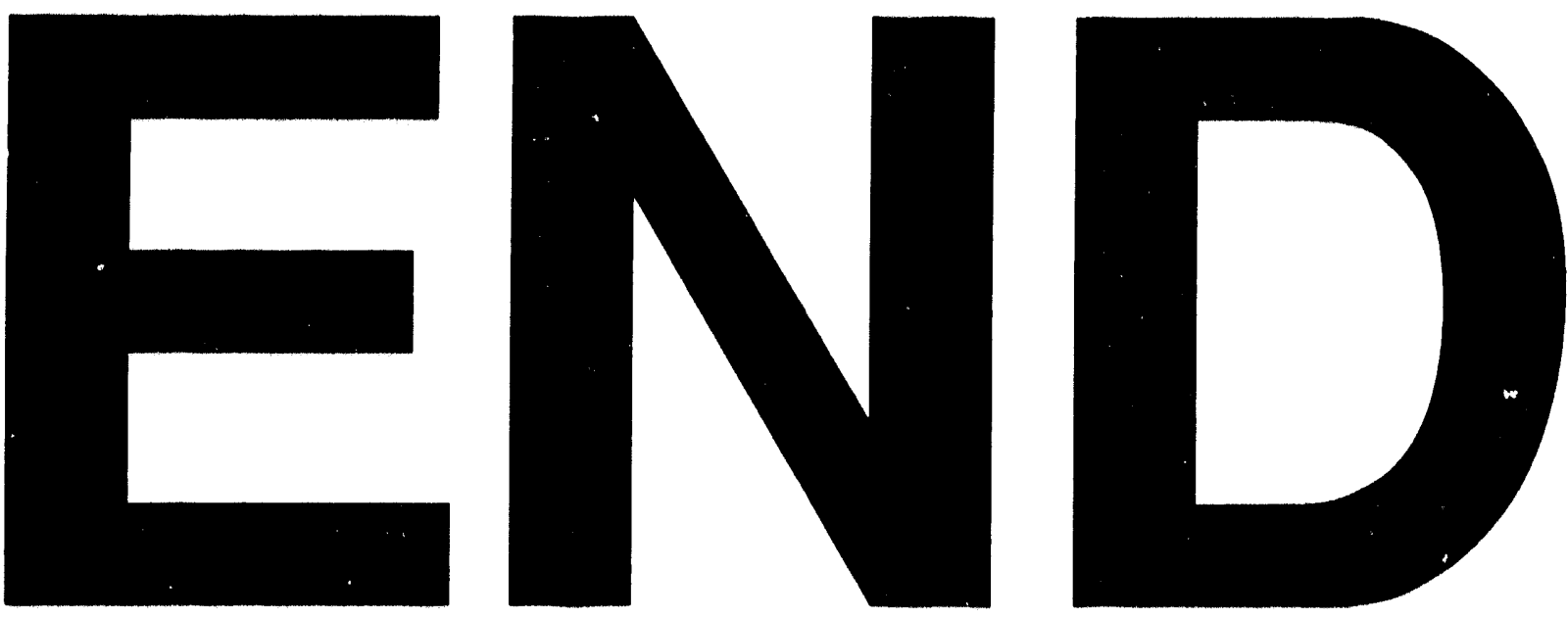
